\title{
Immune ageing at single-cell resolution
}

\section{Denis A. Mogilenko (1) ${ }^{1,2}$, Irina Shchukina ${ }^{1,2}$ and Maxim N. Artyomov $\mathbb{1}^{1 凶}$}

Abstract $\mid$ Ageing leads to profound alterations in the immune system and increases susceptibility to some chronic, infectious and autoimmune diseases. In recent years, widespread application of single-cell techniques has enabled substantial progress in our understanding of the ageing immune system. These comprehensive approaches have expanded and detailed the current views of ageing and immunity. Here we review a body of recent studies that explored how the immune system ages using unbiased profiling techniques at single-cell resolution. Specifically, we discuss an emergent understanding of age-related alterations in innate and adaptive immune cell populations, antigen receptor repertoires and immune cell-supporting microenvironments of the peripheral tissues. Focusing on the results obtained in mice and humans, we describe the multidimensional data that align with established concepts of immune ageing as well as novel insights emerging from these studies. We further discuss outstanding questions in the field and highlight techniques that will advance our understanding of immune ageing in the future.

Ageing is a multimodal process that occurs at several levels, with organs, tissues and cells undergoing substantial and simultaneous remodelling, thus limiting the power of conventional molecular biology approaches to resolve this complexity. Loss of physiological integrity, disturbed tissue homeostasis and increasing deterioration of various biological systems, including the immune system, are among the key features of ageing ${ }^{1}$. Together, these changes reshape physiological and immune landscapes as well as increase vulnerability to some diseases, frailty and multimorbidity ${ }^{2}$. Interestingly, not all immune processes are uniformly sensitive to ageing, suggesting that various immune cell populations are heterogeneously impaired in older organisms (for example, $\geq 65$ years in humans and $\geq 1.5$ years in mice $)^{3}$. The current development of multi-omics and single-cell techniques ${ }^{4}$ (BOX 1) and progress in high-throughput biology and systems immunology $\mathrm{y}^{5}$ make it possible to comprehensively characterize cellular and functional heterogeneity and dynamic changes in the immune system during ageing. Novel techniques, including single-cell RNA sequencing (scRNA-seq) (BOX 2), have confirmed previous findings and expanded existing paradigms in ageing and immunity built on evidence from prior targeted studies. In this Review, we summarize recent advances in our understanding of the ageing immune system and discuss how reported single-cell data and analyses align with existing concepts. We focus our analysis on accumulating single-cell results obtained from mammalian model organisms and, where possible, we discuss how these findings can be translated to immune system ageing in humans (the datasets discussed are available to browse through an Artyomov laboratory webpage).

\section{Inflammageing}

An unresolved systemic inflammation in the absence of pathogens in aged organisms is a hallmark of immune ageing, often referred to as 'inflammageing ${ }^{3,7}$. Inflammageing is characterized by an unbalanced production of pro-inflammatory and anti-inflammatory factors, which is profoundly predictive of death and chronic diseases ${ }^{8}$ (FIG. 1). Although the concept of inflammageing was initially built on measurements of a relatively low number of inflammatory factors, unbiased profiling studies fully corroborate this phenomenon. A recent study combined bulk RNA sequencing of 17 tissues with plasma proteomics at ten time points across the mouse lifespan to identify age-related genes clustered in consistent trajectory groups with coherent biological functions $s^{9}$. In accord with previous results ${ }^{10}$, this analysis identified two distinct gene clusters related to immune responses that are rapidly upregulated on transition from middle to advanced age in mice ${ }^{9}$. These transcriptional alterations likely reflect an active infiltration of immune cells into aged tissues and consequent systemic inflammation. Intriguingly, the breadth of expression changes in these clusters is greatest in adipose tissues, especially in visceral fat depots ${ }^{9}$, suggesting that fat-associated macrophages and adipocytes might be among the key regulators of inflammageing. In addition to immune cell infiltration, inflammageing might result from alterations in basic tissue architecture owing to age-associated remodelling. Broadly, there is enhanced formation of fibrotic structures and senescent cell accumulation in many tissues ${ }^{11-14}$, but some tissues are also characterized by a distinct set of immune alterations. For example, in mice, type I interferon signalling has been 


\section{Box 1 | Multi-omics and single-cell technologies in immunology}

A comprehensive assessment of a set of molecules, such as DNAs, RNAs, proteins and metabolites, is collectively termed 'multi-omics'. Flow cytometry is historically the first single-cell-based technique capable of simultaneously identifying 5-20 characteristics in individual cells. Typically, flow cytometry experiments use fluorescently conjugated antibodies to detect surface and intracellular epitopes and/or fluorescent probes that measure cellular characteristics such as an abundance of DNA, mitochondria, lysosomes and lipid droplets. Mass cytometry, also known as cytometry by time of flight, is a variation of flow cytometry that relies on antibodies labelled with heavy metal ion tags, which allows the measurement of up to 40 individual epitopes in individual cells. During the past decade, unbiased single-cell-based applications of omics have been extensively developed. Single-cell RNA sequencing (scRNA-seq) is a rapidly growing technology that can detect and quantitively measure $500-5,000$ of the most highly expressed transcripts per cell ${ }^{182}$. Computational analysis of transcriptomes of individual cells can identify novel cell populations, activation states and differentiation programmes in immune cells. The variation of the scRNA-seq technique that identifies sequences of variable regions in the T cell receptor or $B$ cell receptor in addition to RNA transcripts in individual cells (termed 'single-cell T cell receptor sequencing' and 'single-cell B cell receptor sequencing') has become instrumental in studying antigen receptor repertoires at single-cell resolution ${ }^{182}$. Cellular indexing of transcriptomes and epitopes by sequencing is a method in which oligonucleotide-labelled antibodies are used to integrate cellular protein and transcriptome measurements into a single-cell readout ${ }^{183}$. It exceeds the limitations of mass cytometry and, theoretically, may extend to measuring thousands of proteins and transcripts simultaneously. Single-cell assay for transposase-accessible chromatin using sequencing was recently developed, and it enables the analysis of epigenetic landscapes of individual cells ${ }^{184,185}$. Moreover, single-cell techniques that combine transcriptional information with epigenetic characteristics in individual cells have been developed ${ }^{186}$. An important limitation of these single-cell methods is that they use cell suspensions or isolated nuclei and require disaggregation of an organ, which leads to loss of spatial information relating to the anatomical localization of cells. Adding the positional information to singlecell experiments is the next frontier in the field of multi-omic immunology. Thus, spatial applications of mass cytometry (imaging mass cytometry) ${ }^{187}$ and spatial transcriptomics ${ }^{188}$ are rapidly growing fields that will help to integrate transcriptional and proteomic information in tissue sections to combine multimodal characteristics of individual cells or groups of cells with the complexity of tissue architecture.

reported to increase with age, specifically in the choroid plexus, a tissue that produces cerebrospinal fluid. This inflammatory remodelling is associated with cognitive decline in ageing ${ }^{10}$.

\section{Effects of ageing on myeloid cells}

Ageing is associated with a gradual expansion of circulating myeloid cell populations relative to lymphoid cell populations ${ }^{15}$ (TABLE 1). In part, this shift is due to a decline in thymic activity required for the generation of nascent $\mathrm{T}$ cells ${ }^{16}$. At the same time, there is a differential effect of age on early myelopoiesis and lymphopoiesis in the bone marrow ${ }^{17}$. Changes in the bone marrow of aged mice lead to clonal skewing of haematopoie-

Senescent cell

A terminally differentiated cell characterized by irreversible

cell cycle arrest and a specific secretory profile that develops in response to various stress triggers and accumulates in aged organisms

\section{Caloric restriction}

A dietary intervention that reduces average daily caloric

intake below typical or habitual levels, while containing

essential nutrients and not

leading to malnutrition. tic stem cells (HSCs) towards the myeloid lineage ${ }^{18,19}$. RNA sequencing analysis of the bone marrow stromal microenvironment in mice revealed an age-driven progressive upregulation of pro-inflammatory genes (including $I l 6$ and $I l 1 b$ ), which can shift the balance towards HSCs with myeloid potential ${ }^{20}$. Indeed, analysis of the young bone marrow microenvironment at single-cell resolution demonstrated that stress-induced changes in molecular pathways (such as downregulation of the Notch ligands Delta-like proteins encoded by $D l l 1$ and Dll4) also initiate the myeloid transcriptional programme in mouse $\mathrm{HSCs}^{21}$. It is plausible that these and other similar stress-related molecular circuits underlie the accumulation of myeloid-biased HSCs in haematopoietic niches during ageing. Nevertheless, these developmental shifts do not imply the emergence of inflammageing directly. For instance, ageing of humans does not appear to be associated with an active shift of circulating monocytes to a pro-inflammatory phenotype, given that these cells show similar transcriptional profiles in young and old healthy individual $\mathrm{s}^{22,23}$. Further studies of human HSC ageing at single-cell resolution are needed to better understand how myelopoiesis is regulated in aged individuals.

Ageing is also associated with alterations in subpopulations of tissue-resident myeloid cells (FIG. 2). scRNA-seq analyses revealed substantial heterogeneity among tissue-resident myeloid cells, especially in response to inflammation ${ }^{24-27}$, and showed increased proportions of interstitial macrophages expressing chemokine receptor genes $\mathrm{Ccr} 2$ and $\mathrm{Cx} 3 \mathrm{cr} 1$ but reduced proportions of alveolar macrophages in aged mice ${ }^{25}$ (TABLE 1). Moreover, alveolar macrophages in aged mice highly express genes that contribute to inflammageing, such as Spp1 (which encodes osteopontin) and $\mathrm{Ccl} 3$ (REF. ${ }^{27}$ ). In line with this, the proportions of fetal-derived tissue-resident macrophages markedly decrease in aged mouse mammary tissues. By contrast, the proportions of macrophages that arise from bone marrow-derived myeloid precursors are not changed, but these cells show increased expression of pro-inflammatory genes (such as $C c l 5$ and $G d f 15)^{28}$. In the peritoneal cavity, scRNA-seq identified markedly reduced numbers of large peritoneal macrophages (which originate from embryonic precursors and express Icam2) in old mice versus young mice ${ }^{25}$, as previously observed by means of flow cytometry ${ }^{29,30}$. Moreover, single-cell analysis of ageing mice demonstrated increased inflammatory function (including expression of the cytokine gene Il1b) of liver-resident macrophages (also known as Kupffer cells), which likely contributes to hepatic inflammation and damage ${ }^{26}$. Thus, the tissue environment in aged mice is generally associated with a substitution of tissue-resident subsets of macrophages originating from embryonic precursors for monocyte-derived populations. Their transcriptional programmes shift towards pro-inflammatory phenotypes, contributing to inflammageing. It is crucial to further understand the fate of these macrophage lineages in various organs during human ageing, and one important resource is a recently published dataset dissecting the development of human tissue-resident macrophages at single-cell resolution ${ }^{31}$.

To a certain degree, pro-inflammatory shifts of myeloid cell populations in old organisms might depend on effects of ageing on physiological processes and might be ameliorated by systemic interventions, such as dietary restrictions, including caloric restriction ${ }^{32}$. Recent single-cell transcriptomics analysis of the effects of caloric restriction on multiple tissues in ageing rats showed that caloric restriction represses age-related inflammation ${ }^{33}$. Specifically, that study demonstrated that caloric restriction reverses the proinflammatory polarization of aged M1 macrophages, increases the proportions of anti-inflammatory macrophages with high phagocytic activity and modifies 
M1 macrophages

An historical, overly simplistic, classification of pro-

inflammatory macrophages

activated in vitro with

interferon- $\gamma$ (IFN $\gamma)$ and

lipopolysaccharide that

only partially reflects the

heterogeneity of highly

specialized, dynamic and

heterogeneous macrophage

subsets in vivo, the activation

of which is continuously

shaped by multiple matrix

and cellular signals in the

tissue microenvironment. ligand-receptor-dependent communication between macrophages and stromal cells ${ }^{33}$. Further studies are needed to translate the effect of caloric restriction and similar interventions to myeloid cell populations in ageing individuals.

Neutrophils are also important myeloid cells, which although generally short-lived may also be affected by ageing. Neutrophil development and numbers seem to be unaltered systemically by ageing, yet neutrophils show a decline in phagocytic activity and killing of bacteria in elderly humans ${ }^{34}$. Furthermore, recent studies showed that age-related changes in the tissue environment could reprogramme neutrophils. Thus, in mice, ageing interferes with transepithelial migration of neutrophils in injured tissues via a process regulated by CXC-chemokine ligand 1 (CXCL1), resulting in aberrant neutrophil trafficking and subsequent remote organ damage ${ }^{35}$. CXCL1 also recruits neutrophils to the liver in aged mice, where they induce tissue senescence and inflammation via the production of reactive oxygen species ${ }^{36}$. This crosstalk between the inflammageing-associated chemokine CXCL1, tissue damage and aberrant neutrophil functions possibly contributes to the development of age-related chronic inflammation and can be further studied in the context of exacerbated pulmonary and hepatic chronic diseases in ageing individuals. Furthermore, a recent multi-omics profiling study demonstrated that age-associated neutrophil remodelling is evident in bone marrow-residing neutrophils ${ }^{37}$, suggesting a role for the aged bone

\section{Box 2 | Single-cell RNA sequencing}

Single-cell RNA sequencing (scRNA-seq) approaches recently evolved owing to rapid progress in next-generation sequencing technologies. Single-cell isolation is the first step of scRNA-seq. Historically, fluorescence-activated cell sorting of hundreds of individual cells was one of the early strategies that rely on the availability of monoclonal antibodies that recognize proteins expressed on the cells of interest. As a more efficient variant, microfluidic technologies have recently become popular for the low-cost isolation of individual cells. One of the microfluidic technologies, Fluidigm C1, provides single-cell isolation, RNA extraction and cDNA synthesis for up to 800 cells on a single chip ${ }^{189}$. A popular alternative for single-cell isolation is microdroplet-based microfluidics ${ }^{190}$. This approach allows the dispersion of liquid droplets in an oil phase, requires lower volumes than standard microfluidic chips and can screen thousands to millions of cells. An example of a commercial microdroplet-based microfluidics system is the Chromium system from 10X Genomics, which can take a suspension of cells or nuclei as an input. Consequent steps include cell lysis, first-strand cDNA synthesis by reverse transcription of mRNA, second-strand synthesis and cDNA amplification by PCR to generate scRNA-seq libraries. Some scRNA-seq methods produce full-length coverage across transcripts (such as Smart-Seq2 (REF. $\left.{ }^{191}\right)$ ), whereas other methods limit sequencing coverage to $3^{\prime}$ or $5^{\prime}$ regions of mRNAs (such as $10 X$ Genomics). The most popular approaches to make scRNA-seq libraries are also limited by capturing only mRNA with poly(A) tails. Although bulk RNA-seq allows almost genome-wide detection levels of mRNA expression in pooled cell samples, scRNA-seq cannot measure the expression levels of most genes in individual cells. Indeed, the sequencing depth usually allows reliable identification of limited numbers of highly expressed transcripts per single cell (usually $1,000-5,000$ individual transcripts). Because of the ongoing development of scRNA-seq techniques, different generations can differ in sequencing depth and create technical limitations to compare results from early versions versus late versions of scRNA-seq. In the latest versions, incorporation of unique molecular identifiers (random 10-16-bp sequences, also known as barcodes) in the reverse transcription step removes bias from PCR amplification steps and increases sequencing accuracy. A more detailed analysis of applications of scRNA-seq to analyse the immune system is presented in recent excellent reviews ${ }^{4,182}$. marrow microenvironment in age-associated neutrophil dysregulation.

Among other cellular phenotypes linked to ageing, disturbed phagocytic activities of neutrophils, macrophages and dendritic cells (DCs) and their reduced capacity to engulf apoptotic cells via efferocytosis have been described in mice and humans ${ }^{38-40}$. In old mice, conventional type 1 dendritic cells, but not conventional type 2 dendritic cells, are decreased in abundance in the spleen $^{25}$. However, it remains controversial whether aged dendritic cell subtypes demonstrate specific alterations in antigen presentation capacity ${ }^{41}$.

\section{Effects of ageing on innate lymphocytes}

Innate lymphoid cells (ILCs) include natural killer (NK) cells, group 1 ILCs (ILC1s), group 2 ILCs (ILC2s) and group 3 ILCs $^{42}$. ILCs play a unique role in tissue immunity via cytokine secretion and interaction with other immune and stromal cells. However, surprisingly little is known about the role of ILCs in the homeostasis of aged tissues. Age-related changes in NK cells in older humans ( $\geq 60$ years) include a shift towards a maturer $\mathrm{CD} 14^{+} \mathrm{CD} 56^{\mathrm{hi}}$ subset, coupled with diminished cytokine secretion, cytotoxicity and especially the release of perforin ${ }^{43-45}$. At least some of the age-associated alterations in NK cell functions are programmed by the aged environment in mice. Indeed, NK cell transfer experiments show that the aged environment interferes with $\mathrm{NK}$ cell maturation and proliferation ${ }^{46}$. In line with these observations, scRNA-seq analysis of immune cells from the spleen, lungs and liver demonstrated a decrease in NK cell proportions in old mice ${ }^{25}$. These data suggest a general ability of an aged environment to suppress NK cell homeostasis. It is possible that the decreased NK cell numbers contribute to impaired antiviral immunity in older organisms ${ }^{43}$. Intriguingly, tissue-specific proliferation and accumulation of NK cells was shown to occur in distinct aged niches, such as the dentate gyrus neurogenic niche of human and mouse aged brains. scRNA-seq analysis of NK cells in the aged dentate gyrus revealed features of increased activation and cytotoxicity ${ }^{47}$. Moreover, mouse NK cells eliminate senescent neuroblasts and mediate age-related decline in cognitive function ${ }^{47}$, providing a striking example of a deleterious effect of NK cells in old organisms.

ILC1s are non-cytotoxic cells that produce interferon- $\gamma$ $(\mathrm{IFN} \gamma)$ and function as the first line of defence against viruses and certain bacteria ${ }^{48}$. Similarly to NK cells, hepatic ILC1 numbers decrease in old mice ${ }^{25}$. Tissueresident liver ILC1s develop locally from $\mathrm{SCA}^{+} \mathrm{MAC1}^{+}$ HSCs via a mechanism driven by IFN $\gamma^{49}$. It remains unclear which signals from the aged environment disturb ILC1 development and whether ILC1s in other organs are affected in old mice and humans. ILC2s are involved in innate immune responses against parasites and regulate tissue homeostasis ${ }^{42}$. Single-cell analyses in mice showed that ILC2s are less abundant in old lungs ${ }^{25}$ and adipose tissue $\mathrm{e}^{50}$. However, the decrease in ILC2 populations is not a universal hallmark of ageing; for example, the numbers of ILC2s increase in aged mouse brains ${ }^{51}$. Ageing increases early bone marrow development of ILC2s, and the decline in tissue ILC2 


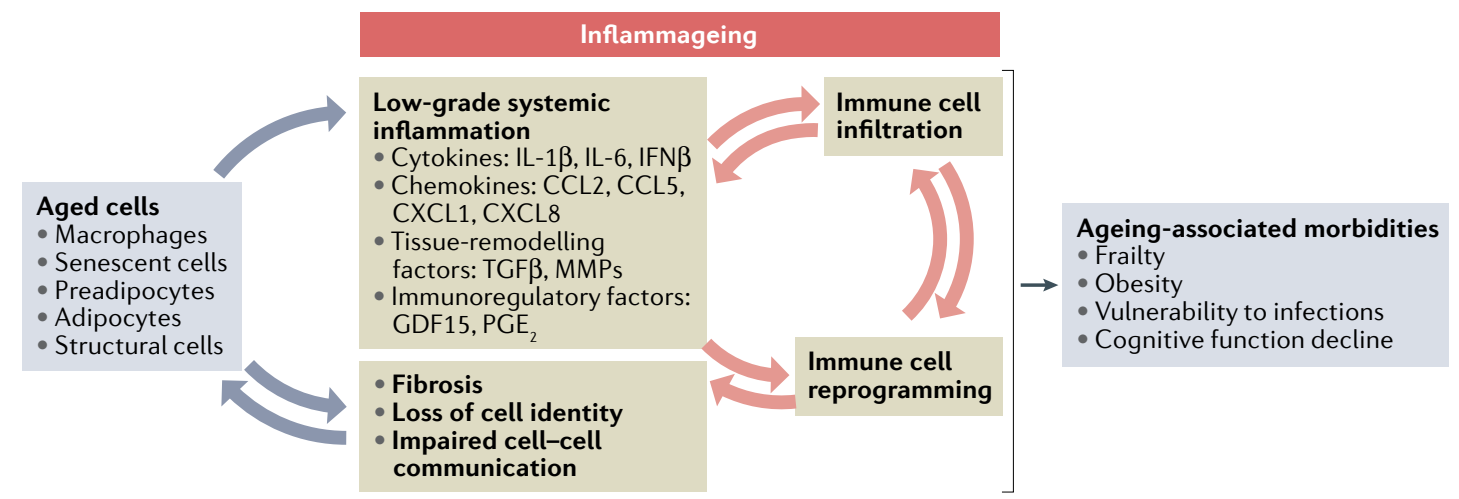

Fig. 1 | Cellular and molecular components of inflammageing. Low-grade chronic systemic inflammation, or inflammageing, comprises multiple inflammatory factors that originate from various cellular sources in aged organisms. Aged pro-inflammatory tissue macrophages produce cytokines and chemokines ${ }^{168}$, and senescent cells secrete a plethora of pro-inflammatory components and matrix metalloproteinases (MMPs) as components of the senescence-associated secretory phenotype ${ }^{113,114}$. Moreover, non-immune cells, such as adipocytes, preadipocytes and stromal cells (including fibroblasts and endothelial cells), contribute to inflammageing by secreting soluble inflammatory factors and altering the tissue microarchitecture of aged organs ${ }^{7}$. The pro-inflammatory chemokines drive excessive immune cell infiltration in tissues, where the cytokines (such as IL- 6 and IL-1 $\beta$ ) and immunoregulatory factors (such as prostaglandin $\mathrm{E}_{2}\left(\mathrm{PGE}_{2}\right)$ ) reprogramme immune cell subsets to a more pro-inflammatory and dysfunctional state ${ }^{169,170}$. In turn, the dysfunctional immune cells, including macrophages and T cells, amplify the inflammatory and destructive processes in ageing tissues ${ }^{169,171,172}$. This crosstalk between cellular and molecular components of inflammageing ultimately results in a progressive functional decline in various organs and leads to age-associated diseases. CCL, CC-chemokine ligand; CXCL, CXC-chemokine ligand; GDF15, growth/differentiation factor 15; IFN $\beta$, interferon- $\beta$; TGF $\beta$, transforming growth factor- $\beta$.

populations might be due to dysfunctional migratory cues $^{52}$. Functionally, ILC2s appear to be associated with healthier ageing phenotypes. In old adipose tissues, a decrease in the numbers of ILC2s is linked to a metabolic impairment and cold-induced lethality exacerbated in old mice ${ }^{50}$, whereas in the ageing brain, ILC2s function to counteract cognitive decline ${ }^{51}$. ILC2s have been found in human adipose tissue $\mathrm{e}^{53}$, but it remains unclear whether they contribute to age-associated metabolic dysfunction in ageing individuals.

\section{Effects of ageing on T cells}

Age-associated $\mathrm{CDB}^{+}$memory $\mathrm{T}$ cells. Essential for antiviral and antitumour immunity, $\mathrm{CD}^{+} \mathrm{T}$ cells are substantially affected by ageing in both mice and humans. In general, older age has been associated with a loss of naive $\mathrm{CD}^{+} \mathrm{T}$ cells coupled with an increase in memory subsets and an overall increase in clonally ${ }^{54-56}$. Most recently, age-associated remodelling of the mouse immune $\mathrm{T}$ cell compartment was comprehensively characterized by scRNA-seq and single-cell T cell receptor (TCR) sequencing of four tissues (spleen, peritoneum, lungs and liver $)^{25}$. These data confirmed a decrease in the abundance of naive $\mathrm{CD} 8^{+} \mathrm{T}$ cells across the four tissues and defined a distinct age-associated CD8 ${ }^{+}$ $\mathrm{T}$ cell subpopulation (referred to by the study authors as 'Taa cells') uniquely characterized by co-expression of the checkpoint receptor PD1 and the transcription factor $\mathrm{TOX}^{25}$. Although absent in young mice, these age-associated $\mathrm{PD} 1^{+} \mathrm{TOX}^{+} \mathrm{CD}^{+} \mathrm{T}$ cells accumulate in multiple tissues in old animals, including the spleen, liver, lungs and fat. They constitute up to $60 \%$ of all $\mathrm{CD}^{+} \mathrm{T}$ cells in these tissues and are a striking example of systematic changes in the ageing immune system that affect multiple tissues. This observation is consistent with the organ-wide single-cell resolution profiling data produced by the Tabula Muris Senis Consortium and Calico Life Sciences ${ }^{26,57}$, although these studies did not perform a detailed analysis of $\mathrm{CD} 8^{+} \mathrm{T}$ cell ageing. The age-associated $\mathrm{CD}^{+} \mathrm{T}$ cells exhibit a phenotype of $\mathrm{T}$ cell exhaustion characterized by high expression levels of TOX, PD1, lymphocyte activation gene 3 protein (LAG3) and T cell immunoreceptor with immunoglobulin and ITIM domains (TIGIT) ${ }^{25}$, which generally suggests a loss of classical effector functions ${ }^{58,59}$. However, upon TCR stimulation, they produce a distinct set of pro-inflammatory molecules such as granzyme $\mathrm{K}$ (GZMK) and CCL5 (REF. ${ }^{25}$ ). This observation suggests a functional role for these cells in murine ageing as a source of pro-inflammatory signals that might be particularly important in the context of old tissue remodelling or under conditions of an acute infection.

In humans, most of the studies focus on the ageing of circulating CD8 ${ }^{+} \mathrm{T}$ cells and use mass cytometry and scRNA-seq to analyse peripheral blood mononuclear cells (TABLE 1). For example, recent scRNA-seq studies of healthy donors reported a twofold decrease in the naive $\mathrm{CD}^{+}$ $\mathrm{T}$ cell fraction of peripheral blood mononuclear cells from old individuals compared with young individuals ${ }^{60,61}$. Another study used cellular indexing of transcriptomes and epitopes by sequencing (CITE-seq) to characterize old and young peripheral blood mononuclear cells and also demonstrated an age-associated decrease in the abundance of naive $\mathrm{CD} 8^{+} \mathrm{T}$ cells and significant remodelling of the $\mathrm{T}$ cell memory compartment ${ }^{25}$. Specifically, in healthy lean individuals, GZMK-expressing, but not granzyme B (GZMB)-expressing, $\mathrm{CD}^{+}$effector memory $\mathrm{T}$ cells ( $\mathrm{T}_{\mathrm{EM}}$ cells) proportionally increase in abundance with age relative to overall $\mathrm{CD} 8^{+} \mathrm{T}$ cells ${ }^{25}$. A recent mass cytometry study of a large cross-sectional 
Table 1 | Changes in main immune cell populations in ageing

\begin{tabular}{|c|c|c|}
\hline $\begin{array}{l}\text { Immune cell } \\
\text { population }\end{array}$ & Age-associated changes & $\begin{array}{l}\text { Methods used } \\
\text { for analysis }\end{array}$ \\
\hline \multicolumn{3}{|l|}{ Mice } \\
\hline Monocytes & Increased abundance in the spleen and blood ${ }^{135,136}$ & Flow cytometry \\
\hline Macrophages & $\begin{array}{l}\text { Decreased abundance of alveolar macrophages with reduced proliferative capacity } \\
\text { and phagocytosis }{ }^{25,150,151} \\
\text { Increased abundance of } F n 1^{+} \mathrm{C} c r 2^{+} \text {interstitial macrophages } \\
\text { Decreased abundance of peritoneal macrophages } \\
\text { Increased abundance of } \mathrm{CX}_{3} \mathrm{CR} 1^{+} \text {macrophages in the liver }{ }^{25} \text { and kidney }{ }^{152} \\
\text { Increased abundance of fetal-derived macrophages in mammary tissue }{ }^{28}\end{array}$ & $\begin{array}{l}\text { scRNA-seq, } \\
\text { flow cytometry, } \\
\text { microscopy }\end{array}$ \\
\hline DCs & $\begin{array}{l}\text { Decreased abundance of cDC1s in the spleen }{ }^{25} \\
\text { Decreased abundance of cDC2s in the peritoneum } \\
\text { Decreased abundance of pDCs in the spleen }{ }^{25,153} \text { and liver }^{25}\end{array}$ & $\begin{array}{l}\text { scRNA-seq, } \\
\text { flow cytometry }\end{array}$ \\
\hline Neutrophils & Increased abundance in the lungs and liver 55,27 & $\begin{array}{l}\text { scRNA-seq, } \\
\text { flow cytometry }\end{array}$ \\
\hline ILCs & $\begin{array}{l}\text { Decreased abundance of NK cells in the spleen, peritoneum, lungs and liver }{ }^{25} \\
\text { Increased abundance of NK cells in neurogenic niches }{ }^{47} \\
\text { Decreased abundance of ILC1s in the liver } \\
\text { Decreased abundance of ILC2s in the lungs } \\
\text { Increased abundance of ILC2s in the brain }\end{array}$ & $\begin{array}{l}\text { scRNA-seq, } \\
\text { flow cytometry, } \\
\text { microscopy }\end{array}$ \\
\hline B cells & $\begin{array}{l}\text { Increased abundance of age-associated B cells in the spleen and meninges } \\
\text { Increased abundance of plasma B cells in the kidney, adipose tissue and bone } \\
\text { marrow } \\
\text { Accumulation of } \mathrm{Apoe}^{+} \text {age-associated B cells in the spleen }{ }^{57} \\
\text { Accumulation of } Z \text { Ztb32 } 2^{+} \text {age-associated B cells in the spleen }{ }^{25} \\
\text { Increased abundance of Zcwpw } 1^{+} \text {B1 cells in the peritoneum }{ }^{25}\end{array}$ & $\begin{array}{l}\text { scRNA-seq, } \\
\text { flow cytometry }\end{array}$ \\
\hline$\gamma \delta \mathrm{T}$ cells & $\begin{array}{l}\text { Increased abundance of } \mathrm{V} 6^{+} \text {cells in lymph nodes } \\
\text { Decreased abundance of Sox } 4^{+} \text {cells in the spleen } \\
\text { Increased abundance in the lungs and liver }{ }^{25}\end{array}$ & $\begin{array}{l}\text { scRNA-seq, } \\
\text { flow cytometry }\end{array}$ \\
\hline $\mathrm{CD}^{+} \mathrm{T}$ cells & $\begin{array}{l}\text { Decreased abundance of naive cells in the spleen, peritoneum and lungs } \mathrm{s}^{25,154} \\
\text { Increased abundance of exhausted-like PD1 }{ }^{+} \text {cells in the spleen, peritoneum, lungs } \\
\text { and liver } \mathrm{r}^{25,69} \\
\text { Increased abundance of cytotoxic cells in the spleen }{ }^{69} \\
\text { Increased abundance of activated } \mathrm{T}_{\text {reg }} \text { cells in the spleen }{ }^{25,69,154} \text { and adipose tissue }{ }^{155}\end{array}$ & $\begin{array}{l}\text { scRNA-seq, } \\
\text { flow cytometry }\end{array}$ \\
\hline CD8 ${ }^{+} \mathrm{T}$ cells & $\begin{array}{l}\text { Decreased abundance of naive cells in the spleen, peritoneum and lungs }{ }^{25,156} \\
\text { Increased abundance in neurogenic niches }{ }^{157} \\
\text { Increased abundance of virtual memory cells in the spleen, blood and lymph nodes }{ }^{156,158} \\
\text { Increased abundance of a CD } 49 \mathrm{~d}^{+} \text {subset in the spleen }{ }^{159} \\
\text { Accumulation of exhausted-like PD1 } 1^{+} \text {cells in the spleen, peritoneum, lungs, liver, } \\
\text { kidney, adipose tissue, meninges and blood }{ }^{25,160}\end{array}$ & $\begin{array}{l}\text { scRNA-seq, } \\
\text { flow cytometry }\end{array}$ \\
\hline \multicolumn{3}{|l|}{ Humans } \\
\hline Monocytes & $\begin{array}{l}\text { Increased abundance in the blood }{ }^{25,60,161} \\
\text { Increased abundance of non-classical CD } 14^{+} \mathrm{CD} 16^{+} \text {cells in the blood }{ }^{162}\end{array}$ & Flow cytometry \\
\hline DCs & Decreased abundance of pDCs in the blood ${ }^{162}$ & Flow cytometry \\
\hline B cells & $\begin{array}{l}\text { Decreased abundance of } \mathrm{B} 1 \text { cells }\left(\mathrm{CD} 19^{+} \mathrm{CD} 20^{+} \mathrm{CD} 27^{+} \mathrm{CD} 38^{\text {low/mid }} \mathrm{CD} 43^{+}\right) \text {in the } \\
\text { blood }^{163} \\
\text { Decreased abundance of the } Z B T B 32^{+}\left(\mathrm{CD} 27^{+} \mathrm{CD} 38^{\text {low/mid }}\right) \text { subset in the blood }{ }^{25}\end{array}$ & $\begin{array}{l}\text { scRNA-seq, } \\
\text { flow cytometry }\end{array}$ \\
\hline MAIT cells & Decreased abundance in the blood ${ }^{25,164}$ & $\begin{array}{l}\text { scRNA-seq, } \\
\text { flow cytometry }\end{array}$ \\
\hline$\gamma \delta$ T cells & $\begin{array}{l}\text { Decreased abundance in the blood }{ }^{165} \\
\text { Decreased abundance of } \mathrm{V}^{+} 2^{+} \mathrm{V}^{+}{ }^{+} \text {cells in the blood } 25,166,167 \\
\text { Decreased abundance of } \mathrm{SO} X 4^{+} \text {cells in the blood } \\
\end{array}$ & $\begin{array}{l}\text { scRNA-seq, } \\
\text { flow cytometry }\end{array}$ \\
\hline
\end{tabular}


Table 1 (cont.) | Changes in main immune cell populations in ageing

\begin{tabular}{|c|c|c|}
\hline $\begin{array}{l}\text { Immune cell } \\
\text { population }\end{array}$ & Age-associated changes & $\begin{array}{l}\text { Methods used } \\
\text { for analysis }\end{array}$ \\
\hline \multicolumn{3}{|c|}{ Humans (cont.) } \\
\hline CD4 ${ }^{+} T$ cells & $\begin{array}{l}\text { Decreased abundance of naive cells in the blood }{ }^{60,61,137,138} \\
\text { Increased abundance of } \mathrm{T}_{\mathrm{EM}} \text { cells in the blood }{ }^{138} \\
\text { Decreased abundance of recent thymic emigrants in the blood }{ }^{137} \\
\text { Decreased abundance of an interferon-activated subset in the blood } \\
\text { Increased abundance of the cytotoxic subset in the blood (supercentenarians) }\end{array}$ & $\begin{array}{l}\text { scRNA-seq, } \\
\text { flow cytometry }\end{array}$ \\
\hline CD8 ${ }^{+} T$ cells & $\begin{array}{l}\text { Decreased abundance of naive cells in the blood }{ }^{25,61,138} \\
\text { Increased abundance of } \mathrm{T}_{\mathrm{EM}} \text { cells in the blood }{ }^{25,138} \\
\text { Increased abundance of the } \mathrm{GZMK}{ }^{+}\left(\mathrm{CD} 28^{+} \mathrm{CD} 57^{-}\right) \text {subset of } \mathrm{T}_{\mathrm{EM}} \text { cells in the blood } \\
\text { Increased abundance of the } \mathrm{CD} 57^{+} \text {subset in the blood }{ }^{149}\end{array}$ & $\begin{array}{l}\text { scRNA-seq, } \\
\text { flow cytometry, } \\
\text { mass cytometry }\end{array}$ \\
\hline
\end{tabular}

ageing cohort of 156 healthy individuals confirmed these observations and found that GZMK-expressing $\mathrm{CD}^{+} \mathrm{T}$ cells gradually increase in abundance in the circulation with age along with $\mathrm{CD} 8^{+}$central memory $\mathrm{T}_{\text {cells }}{ }^{61}$. Of note, $\mathrm{GZMK}^{+} \mathrm{CD} 8^{+} \mathrm{T}$ cells express $\mathrm{CD} 28$ but lack CD57 and are distinct from CD45RA ${ }^{+} \mathrm{T}_{\mathrm{EM}}$ cells the age-associated expansion of which was reported in cytomegalovirus-exposed older individuals (range 21-96 years) ${ }^{62}$ but was not significant in a cohort of healthy donors (range 25-80 years) ${ }^{61}$.

Although GZMK-expressing human $\mathrm{CD}^{+} \mathrm{T}_{\mathrm{EM}}$ cells are similar to the mouse age-associated $\mathrm{PD}^{+} \mathrm{TOX}^{+}$ $\mathrm{GZMK}^{+} \mathrm{CD}^{+} \mathrm{T}$ cells in some aspects (such as high expression of EOMES and GZMK), in humans this cell subpopulation cannot be identified solely on the basis of expression of PD1 (REFS ${ }^{25,61}$ ). This difference between mouse and human $\mathrm{CD}^{+} \mathrm{T}$ cell ageing landscapes might arise because, unlike laboratory mice, humans experience multiple immune challenges during their lifespan, which forms a broader and more phenotypically diverse pool of antigen-experienced memory T cells.

Effect of ageing on $\mathrm{CD4}^{+}$T cells. Similarly to $\mathrm{CD}^{+} \mathrm{T}$ cells, the proportion of naive $\mathrm{CD}^{+} \mathrm{T}$ cells declines and the memory population expands with age in mice and humans $s^{25,63,64}$. This switch to a memory phenotype seems to be driven by a combination of reduced thymic output and cumulative effect of lifelong antigen exposure as $\mathrm{CD}^{+} \mathrm{T}$ cells with transgenic TCRs tend to maintain a naive phenotype even in aged mice ${ }^{63}$. Another long-known feature of age-associated $\mathrm{CD} 4^{+} \mathrm{T}$ cell remodelling is increased abundance of regulatory $\mathrm{T}$ cells $\left(\mathrm{T}_{\text {reg }}\right.$ cells) in the spleen and lymph nodes ${ }^{65-68}$. However, this increase in abundance of $\mathrm{T}_{\text {reg }}$ cells was not observed in ageing lungs or liver of mice ${ }^{25}$. The accumulation of splenic $\mathrm{T}_{\text {reg }}$ cells has been suggested to play a role in restricting immune responses in aged animals (such as compromising control of Leishmania major infection) ${ }^{66,67}$. A recent study used scRNA-seq to dissect the ageing of splenic $\mathrm{CD} 4^{+} \mathrm{T}$ cells in mice and reported that the age-associated increase is not a feature of all $\mathrm{T}_{\text {reg }}$ cells but is instead attributed to a subpopulation of activated $\mathrm{T}_{\text {reg }}$ cells ${ }^{69}$. These activated $\mathrm{T}_{\text {reg }}$ cells are defined by overexpression of Foxp3, Cd81, Cd74 and genes encoding activation markers(such as Tnfrsf9) ${ }^{70}$. Activated $\mathrm{T}_{\text {reg }}$ cells are approximately ten times more abundant in old mice and are superior in suppressive activities in comparison with resting $\mathrm{T}_{\mathrm{reg}}$ cells ${ }^{69}$.

The accumulation of anti-inflammatory activated $\mathrm{T}_{\text {reg }}$ cells is paralleled by a marked expansion of so-called cytotoxic $\mathrm{CD} 4^{+} \mathrm{T}$ cells. These cells are characterized by the expression of Eomes and Gzmk and can produce not only IFN $\gamma$ and tumour necrosis factor (TNF) but also cytotoxic GZMB and perforin upon stimulation ${ }^{69}$. Similarly to activated $\mathrm{T}_{\text {reg }}$ cells, the cytotoxic $\mathrm{CD}^{+} \mathrm{T}$ cell subpopulation was not associated with ageing before the single-cell study but was known in other physiological contexts (reviewed by Takeuchi and Saito ${ }^{71}$ ). Strikingly, scRNA-seq of ageing human $\mathrm{CD}^{+} \mathrm{T}$ cells identified a similar subset of cytotoxic $\mathrm{CD}^{+} \mathrm{T}$ cells that are profoundly expanded at the extreme end of the longevity spectrum in individuals who reached the age of 110 years - supercentenarians ${ }^{72}$. The matching single-cell TCR sequencing data suggested that clonal expansion of $\mathrm{CD} 4^{+} \mathrm{T}$ cells with age is restricted primarily to the subpopulation of cytotoxic $\mathrm{CD}^{+}{ }^{+} \mathrm{T}$ cells. By contrast, other T helper cell subsets remain clonally diverse, even in supercentenarians ${ }^{72}$. Interestingly, cytotoxic $\mathrm{CD} 4^{+} \mathrm{T}$ cell subpopulations are also more abundant in older patients with COVID-19 (range 32-91 years) with moderate symptoms compared with individuals with severe disease ${ }^{61}$, which might indicate that these cells can be beneficial during viral infections.

Finally, ageing is also characterized by increased expression of exhaustion markers by splenic $\mathrm{CD} 4^{+} \mathrm{T}$ cells in mice. Although the concept of $\mathrm{T}$ cell exhaustion is less well established for $\mathrm{CD} 4^{+} \mathrm{T}$ cells than for $\mathrm{CD}^{+} \mathrm{T}$ cells, an age-associated increase in the abundance of $\mathrm{CD} 4^{+}$ $\mathrm{T}$ cells with high levels of inhibitory receptors (such as PD1 and LAG3) has been observed ${ }^{73,74}$. $\mathrm{PD}^{+} \mathrm{CD}^{+}$ $\mathrm{T}$ cells have a memory phenotype and are hyposensitive to TCR stimulation ${ }^{74}$, which matches the canonical 
features of exhausted CD8 ${ }^{+} \mathrm{T}$ cells. Exhausted-like CD4 ${ }^{+}$ $\mathrm{T}$ cells constitute about $30 \%$ of all $\mathrm{CD}^{+} \mathrm{T}$ cells in the spleen of aged mice. Of note, age-associated changes in $\mathrm{CD} 4^{+} \mathrm{T}$ cell subpopulations are not universal across the tissues. scRNA-seq profiles of immune cells across four mouse tissues corroborated the data on splenic $\mathrm{CD}^{+}$ $\mathrm{T}$ cell remodelling and revealed that while accumulation of $\mathrm{PD} 1^{+}$cells was observed in all tissues considered, the expansion of $\mathrm{T}_{\text {reg }}$ cells was evident only in the spleen ${ }^{25}$.

Age-related cell-intrinsic deficiencies of naive $\mathrm{CD} 4^{+}$ $T$ cells have also been described in studies that used aged mice with a transgenic TCR to investigate $\mathrm{CD}^{+} \mathrm{T}$ cell ageing with experimentally controlled antigen exposure.

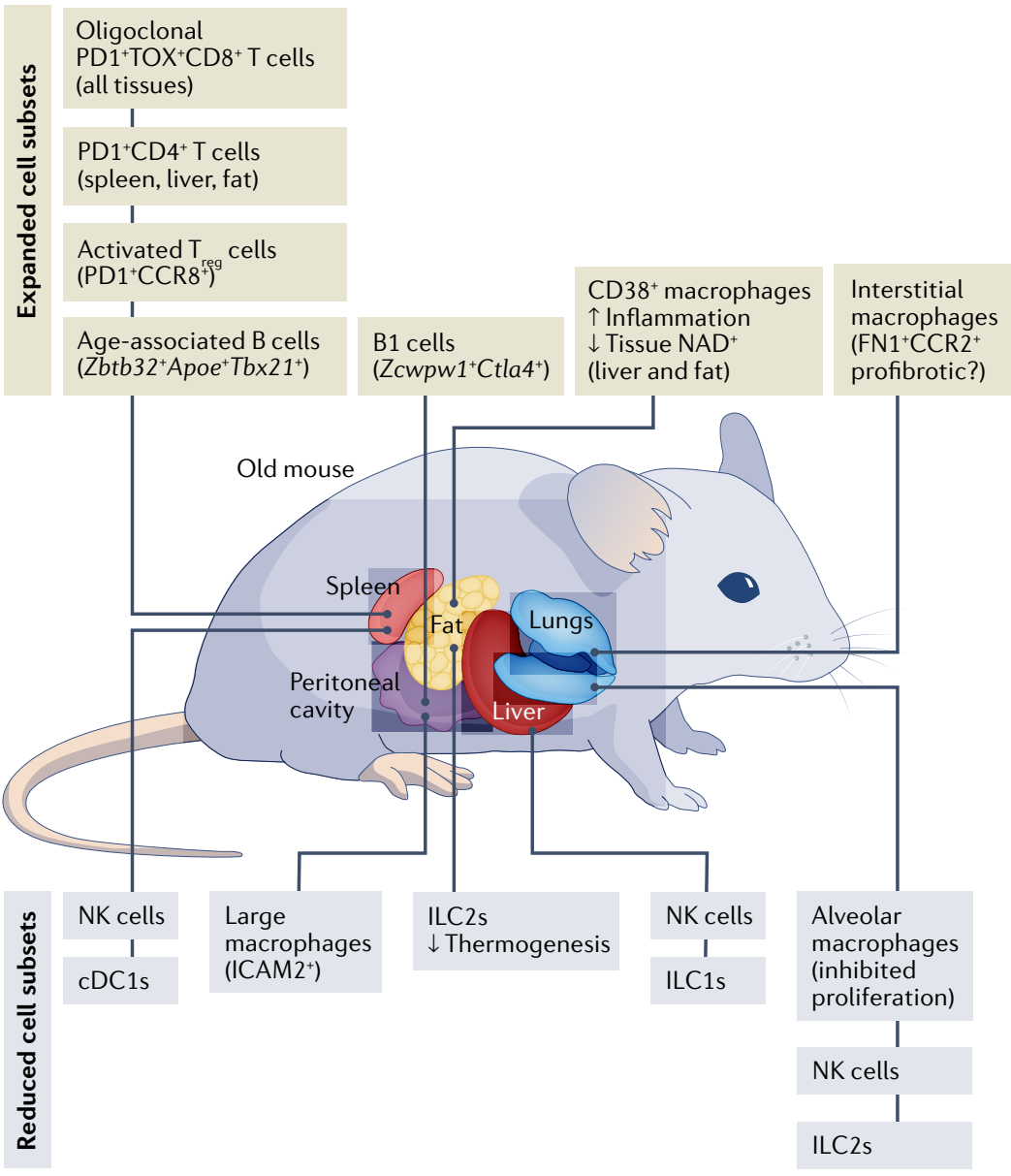

Fig. 2 | Alterations of immune cell populations in ageing. Single-cell techniques identified expanded and reduced immune cell populations with distinct phenotypes in multiple organs of old mice. Exhausted PD $1^{+} \mathrm{TOX}^{+} \mathrm{CD} 8{ }^{+} \mathrm{T}$ cells and activated $\mathrm{PD} 1^{+} \mathrm{CD} 4^{+}$ T cells accumulate across multiple tissues in ageing, whereas natural killer (NK) cells and innate lymphoid cells (ILCs) are among the cell subsets that are reduced in abundance in various organs. Functionally and phenotypically similar CD38 $8^{+}$macrophages expand in metabolically active organs - liver and fat - of old mice ${ }^{173,174}$. Unlike these cell subsets commonly affected by age in many tissues, alterations of other immune cell populations show organ-specific patterns in ageing. For example, activated regulatory T cells $\left(T_{\text {reg }}\right.$ cells) increase in abundance in the spleen of old mice ${ }^{25,69,154}$. Tissue-resident alveolar macrophages decrease in abundance and fibronectin 1-positive ( $\left.\mathrm{FN} 1^{+}\right), \mathrm{CC}$-chemokine receptor 2-positive $\left(\mathrm{CCR}^{+}\right)$interstitial macrophages increase in abundance in the lungs of old mice ${ }^{25,150}$. Distinct subsets of age-associated $B$ cells accumulate in the spleen (B cells expressing Zbtb32, Apoe and Tbx21) and peritoneal cavity (B1 cells expressing Zcwpw1 and Ctla4) of aged mice. cDC1, conventional type 1 dendritic cell; ICAM1, intercellular adhesion molecule 1; ILC1s, group 1 innate lymphoid cells; ILC2s, group 2 innate lymphoid cells.
These studies demonstrated that aged naive $\mathrm{CD} 4^{+} \mathrm{T}$ cells are less responsive to activation in vivo and in vitro than their young counterparts; they have decreased proliferation rates and produce less IL-2 (REFS $\left.{ }^{63,75,76}\right)$. The defect in TCR responsiveness seems to be specific for $\mathrm{CD} 4^{+} \mathrm{T}$ cells that have spent an extended time in circulation because $\mathrm{CD}^{+} \mathrm{T}$ cells from young thymectomized mice exhibit this phenotype, but recent immigrants from either young or aged bone marrow do not ${ }^{77}$. Furthermore, a recent study used scRNA-seq to demonstrate that the responses of naive $\mathrm{CD}^{+} \mathrm{T}$ cells isolated from the spleen of old mice to in vitro stimulation are more heterogeneous and variable on the transcriptional level than those of naive $\mathrm{CD} 4^{+} \mathrm{T}$ cells from young mice, suggesting that activation programmes of aged $\mathrm{CD} 4^{+} \mathrm{T}$ cells are less tightly regulated ${ }^{78}$.

An improper activation has been suggested to drive an incomplete differentiation of aged $\mathrm{CD} 4^{+} \mathrm{T}$ cells into Thelper $1\left(\mathrm{~T}_{\mathrm{H}} 1\right)$ and $\mathrm{T}_{\mathrm{H}} 2$ effector cells ${ }^{76}$. At the same time, the ability of aged $\mathrm{CD} 4^{+} \mathrm{T}$ cells to acquire a $\mathrm{T}_{\mathrm{H}} 17$-type phenotype is not compromised, creating an imbalance and a skew towards antimicrobial responses ${ }^{79,80}$. In bulk, splenic $\mathrm{CD} 4^{+} \mathrm{T}$ cells from aged mice and humans produce much more IL-17 than young controls, which might reflect an age-associated accumulation of $\mathrm{T}_{\mathrm{H}} 17$-type memory cells ${ }^{80,81}$. As $\mathrm{T}_{\mathrm{H}} 17$ cells have been implicated in the development of multiple autoimmune conditions, including inflammatory bowel diseases, one can speculate that the second peak of inflammatory bowel disease prevalence that occurs in older adults might be partially ascribed to this skewing of $\mathrm{T}$ cell populations. Indeed, transfer of aged $\mathrm{CD} 4^{+} \mathrm{T}$ cells to Rag1 $^{-/-}$recipients induced severer colitis than transfer of cells from a young donor ${ }^{80}$. However, further research is required to prove a causal relationship between these events. IL-17-producing cells are also over-represented among $\gamma \delta$ T cells in lymph nodes of aged mice, substituting IFN $\gamma$-producing effector $\gamma \delta$ T cells, which are more abundant in young animals ${ }^{82}$. Numbers of $\gamma \delta$ $\mathrm{T}$ cells change with age in a tissue-dependent manner, as demonstrated by a recent single-cell profiling study of multiple mouse tissues. For example, $\gamma \delta$ T cells are less frequent in the aged liver and lungs but not in the spleen ${ }^{25}$. However, under conditions of acute lung inflammation caused by a murine betacoronavirus, old mice show lower numbers of lung $\gamma \delta$ T cells, which could be restored by a ketogenic $\operatorname{diet}^{83}$.

Altogether, the described age-associated differences in $\mathrm{T}$ cell populations appear to be partly responsible for altered humoral responses in old animals. It has been shown that $\mathrm{CD}^{+} \mathrm{T}$ cell help is required to launch a germinal centre reaction and produce high-affinity antibodies $^{84}$. Eaton et al. used an adoptive transfer model to compare germinal centre responses facilitated by naive $\mathrm{CD} 4^{+} \mathrm{T}$ cells from either young mice or old mice with transgenic TCRs ${ }^{85}$. In that study, cell-intrinsic changes in naive $\mathrm{CD} 4^{+} \mathrm{T}$ cells from old donors led to fewer antigen-specific $B$ cells in the germinal centre and reduced production of class-switched antibodies. By contrast, naive $\mathrm{CD} 4^{+} \mathrm{T}$ cells from young mice were sufficient to elicit robust responses in the aged environment. These observations highlight the importance of 
Damage-associated molecular patterns Endogenous molecules released from damaged or dying cells, such as mitochondria and chromatin components, which activate the innate immune system by interacting with pattern recognition receptors such as Toll-like receptors.
$\mathrm{CD}^{+} \mathrm{T}$ cell ageing biology for developing vaccination strategies customized to the state of the aged population.

TCR repertoire. Early studies of TCR repertoire changes during ageing - first using TCR $\beta$ chain-specific antibodies $^{86}$ then by bulk TCR sequencing - suggested that TCR diversity loss is associated with the increased prevalence of memory $\mathrm{T}$ cells that undergo clonal expansion $^{87,88}$ but can also be affected by a modest decrease in TCR diversity of naive T cells ${ }^{88-90}$. Overall, $\mathrm{CD}^{+} \mathrm{T}$ cells show a greater increase in clonality than $\mathrm{CD}^{+} \mathrm{T}$ cells, which is consistent with the more considerable reduction in naive $\mathrm{CD} 8^{+} \mathrm{T}$ cell subpopulations with ageing. scRNA-seq technology provides a unique opportunity to investigate TCR repertoire complexity via direct sequencing of paired $\alpha$-chains and $\beta$-chains at single-cell resolution, which unequivocally defines TCR clones - a feature not available in bulk level analysis, which often uses only $\beta$-chain sequences. In mice, it was recently demonstrated that the accumulation of highly clonal ageassociated $\mathrm{PD}^{+}{ }^{+} \mathrm{TOX}^{+} \mathrm{CD}^{+} \mathrm{T}$ cells is responsible for the clonality increase in the $\mathrm{CD}^{+} \mathrm{T}$ cell compartment ${ }^{25}$. The clonal expansion of these cells is 'idiosyncratic $c^{\text {'91, }}$ meaning that individual mice differ in the specific TCR $\alpha \beta$ chains used by the expanded $\mathrm{T}$ cell clones. Therefore, there might not be a shared 'ageing antigen' sensed by $\mathrm{T}$ cells in all ageing mice. Further studies are needed to decipher single-cell clonality landscapes in older individuals and identify specific age-related antigens that drive the accumulation of distinct memory $\mathrm{T}$ cell subsets.

Effects of ageing on B cells. Remodelling of adaptive immunity during ageing also includes altered B cell composition and function. A phenotypically and functionally separate subset of B cells has been shown to expand in the spleen and bone marrow of aged mice ${ }^{92,93}$. These cells are distinct from the conventional naive and memory B cells and have been termed 'age-associated B cells' Hao et al. defined age-associated B cells as CD43-CD21/ $\mathrm{CD}^{-} 5^{-} \mathrm{CD} 23^{-} \mathrm{B}$ cells ${ }^{92}$, whereas Rubtsov et al. identified age-associated B cells as CD11 $\mathrm{b}^{+} \mathrm{CD} 11 \mathrm{c}^{+} \mathrm{B}$ cells ${ }^{93}$. Interestingly, age-associated B cells express Tbx21 (which encodes T-bet), which makes them similar to the B cells that have been shown to contribute to lupus-like autoimmunity in mice ${ }^{94}$. Although the age-related factors that prime the expansion of these B cell subsets are not entirely understood, a body of evidence suggests that damageassociated molecular patterns, such as debris and chromatin from apoptotic cells, initiate age-associated B cells via the Toll-like receptor 7 (TLR7) or TLR9 axis $^{92,93}$. Once ageassociated B cells are generated, their survival in old mice requires IFN $\gamma$ signalling ${ }^{95}$. Age-associated B cells can contribute to inflammageing by altering immune homeostasis. For example, age-associated B cells secrete IL- 4 and IL-10 on activation ${ }^{92}$ and can present antigens to $\mathrm{T}_{\text {cells }}{ }^{93}$.

Over the past 3 years, several scRNA-seq studies reported age-associated dynamics of B cells across multiple tissues in mice $e^{9,25,26,57,96}$. In a study profiling both immune and non-immune cells from three tissues of young and old mice, Kimmel et al. characterized a distinct cluster of B cells that increases in abundance with age in the spleen ${ }^{57}$. This cluster is identified by the expression of the apolipoprotein gene Apoe, yet the precise identity of this B cell subset in terms of immunological nomenclature has not been specified. The aforementioned scRNA-seq profiling study of mouse immune cells in four tissues $^{25}$ defined an age-associated population of conventional splenic B cells that express the transcription factor genes $T b \times 21$ and $Z b t b 32$ and genes encoding other markers of age-associated B cells (such as $C x c r 3\left(\right.$ REF. $\left.^{97}\right)$ ). This $Z b t b 32^{+} \mathrm{B}$ cell subset also highly expresses Apoe, suggesting a similarity with the age-associated $B$ cell population reported by Kimmel et al. ${ }^{57}$. Single-cell analysis of B cells in the meninges revealed Apoe-expressing age-associated $B$ cells that accumulate at the central nervous system borders in old mice ${ }^{96}$. Analysis of single-cell B cell receptor (BCR) sequencing data provided additional insights into this population. Indeed, splenic age-associated B cells have been recognized as cells displaying characteristics of antigen-experienced B cells with increased somatic hypermutation ${ }^{98}$. Consistently, the cluster of splenic Tbx21-expressing age-associated B cells demonstrates increased BCR clonality while still preserving BCR repertoire diversity ${ }^{25}$.

Another study that used a combination of scRNA-seq and single-cell BCR sequencing also reported a progressive increase in $B$ cell clonality in ageing mice ${ }^{26}$. This increase was attributed to a cluster of cells expressing markers of plasma B cells Jchain, Xbp1 and Derl3 found in the spleen, bone marrow, kidney and fat of aged mice, albeit in tiny proportions $(\sim 0.1 \% \text { in these tissues })^{9}$. Moreover, tracing the cells from this cluster across the mouse lifespan showed that, similarly to age-associated $B$ cells, age-associated plasma B cells initially arise in the bone marrow and spleen and subsequently increase in abundance in peripheral tissues, such as adipose tissue and kidneys, later in life ${ }^{9}$. Functionally, plasma B cells can produce pro-inflammatory cytokines and enhance myelopoiesis in the ageing bone marrow ${ }^{99}$. Interestingly, a phenotypically similar population of plasma B cells increases in abundance in adipose tissue of older humans ( $\geq 70$ years $)^{9}$.

A focused scRNA-seq analysis of immune cells in the peritoneal cavity (a location not included in Tabula Muris Senis ${ }^{26}$ ) identified B1-like cells as heavily accumulating with age and characterized by a very limited BCR repertoire ${ }^{25}$. Highly enriched in $\mathrm{V}_{\mathrm{H}} 11-2$ chains, these BCRs recognize the cell membrane component phosphatidylcholine ${ }^{100}$. Similarly to splenic ageassociated B cells, peritoneal B1-like cells express the transcription factor gene $Z b t b 32$ yet represent a distinct transcriptional cluster characterized by high levels of an exclusive set of genes, including Zcwpw1 and Ctla4 (REFS ${ }^{25,101}$ ). The Biragyn group showed an age-associated accumulation of B1-like cells, which were identified in old mice and humans by surface expression of the TNF ligand superfamily member $4-1 \mathrm{BBL}^{29,102,103}$. Functionally, B1-like cells become more activated with age, serve as potent inducers of cytotoxic $\mathrm{CD} 8^{+} \mathrm{T}$ cells and respond to commensal bacteria ${ }^{29,102,103}$. The insights from single-cell studies expand our understanding of age-associated B cell heterogeneity and point to potential antigen specificity of age-associated B cell subsets and their tissue-specific inflammatory functions in old organisms. 


\section{Role of non-immune cells in immune ageing} Immune functions of stromal cells in ageing. Immune function is not limited to cells of haematopoietic origin, and multiple types of stromal and epithelial cells are equipped to respond to pathogens and partake in immune homeostasis ${ }^{104,105}$. For instance, fibroblasts are critical structural components of most tissues and a stromal cell type extensively studied in pathological states and ageing ${ }^{106,107}$. Transcriptional analysis showed a loss of cell identity by dermal populations of old fibroblasts accompanied by upregulation of inflammatory genes in mice ${ }^{108}$. Similarly, an analysis of transcriptomic and epigenomic changes in aged fibroblasts identified an increased abundance of 'activated fibroblasts' (for example, fibroblasts involved in tissue repair), including pathways related to cytokine signalling and inflammation ${ }^{109}$. In line with these observations in mice, scRNA-seq analysis of human skin fibroblasts demonstrated a higher expression of genes contributing to low-grade inflammation in distinct populations of aged fibroblasts and predicted a decline in cell-cell communications between fibroblasts and other cell types in aged skin ${ }^{110}$.

Endothelial cells line vascular beds and regulate immune trafficking. Ageing appears to substantially modify the inflammatory transcriptional signatures of endothelial cells in various tissues. For instance, single-cell transcriptional profiling of endothelial cells in aged mouse brain prominently implicated altered inflammation and cytokine signalling pathways associated with neurodegenerative disease ${ }^{11}$. Moreover, in mice, a single-cell analysis revealed transcriptional alterations in aged liver sinusoidal endothelial cells, which are essential regulators of immune defence ${ }^{26}$. Finally, communication between endothelial cells and various immune cell types

\section{Box 3 | Cellular senescence and senescent cells}

Cellular senescence is a state of irreversible cell-cycle arrest due to cellular replicative limit, tumour suppression, inflammation, embryogenesis, wound healing or ageassociated loss of regenerative capacity ${ }^{192}$. Cellular senescence has been defined as a stress response to developmental and environmental stimuli, including genotoxic agents, hypoxia, mitochondrial dysfunction, oncogene activation, epigenetic modifiers and cytokines ${ }^{193}$. Senescent cells are a product of cellular senescence and feature a combination of molecular and morphological characteristics. These cells undergo permanent cell-cycle arrest that is distinct from terminal differentiation and quiescence ${ }^{194}$. They have rewired cell-cycle regulatory pathways with a specific phosphorylation profile of cyclin-dependent kinases (CDKs) and upregulated expression of the CDK2 inhibitor p21CIP1 (also known as CDKN1A) and the CDK4/CDK6 inhibitor p16INK4A (also known as $\mathrm{CDKN} 2 \mathrm{~A})^{193}$. Although increased expression of $\mathrm{p} 21 \mathrm{CIP} 1$ and $\mathrm{p} 16 \mathrm{INK} 4 \mathrm{~A}$ is not unique to senescent cells and can be found in, for example, non-senescent macrophages, p21CIP1 and p16INK4A are often used both as markers of senescent cells and as targets to develop genetic models allowing selective elimination of senescent cells $^{132,134,195}$. Morphological characteristics of senescent cells include an enlarged cell size due to a diluted cytoplasmic domain ${ }^{196}$ and increased activity of lysosomal senescence-associated $\beta$-galactosidase - the most widely used histological biomarker of senescent cells ${ }^{197}$. Other features of senescent cells include DNA, protein and lipid damage, dysfunctional mitochondria and lysosomes, and an altered chromatin landscape ${ }^{193}$. Importantly, senescent cells have a specific secretory profile involving excessive secretion of pro-inflammatory cytokines and chemokines, growth modulators, angiogenic factors and matrix metalloproteinases, collectively named the 'senescence-associated secretory phenotype ${ }^{\eta_{113,114}}$. Different components of the senescenceassociated secretory phenotype mediate the communication of senescent cells with immune cells, affect the functions of stromal cells in tissues and contribute to the low-grade systemic inflammatory phenotype in ageing ${ }^{198}$. (including macrophages and T cells) is markedly altered in old tissues, including liver and fat, as was revealed by a single-cell transcriptional analysis in rats ${ }^{33}$.

Senescent cell contribution to inflammageing. Ageing is characterized by a gradual accumulation of senescent cells throughout the body (BOX 3). Senescence is a terminal stage of cell differentiation, often acquired by damaged or stressed cells, that leads to permanent withdrawal from the cell cycle and a switch to a distinct secretome ${ }^{112}$. This secretome, termed the 'senescence-associated secretory phenotype' (SASP) ${ }^{113-116}$, involves the secretion of multiple chemokines, cytokines and growth factors and contributes to low-grade systemic inflammation in ageing ${ }^{117}$. Although a core transcriptional signature of senescent cells in vitro has been described ${ }^{118}$, no robust approach to determine the transcriptional landscape of senescent cells in vivo has been developed to date. Moreover, senescent cells are profoundly variable in their expression of regulatory and SASP genes even in vitro ${ }^{119}$. Nonetheless, recent scRNA-seq analyses provided some insights into the development of senescent cells in ageing mice. The scRNA-seq atlas of ageing mouse tissues (Tabula Muris Senis) showed that the fraction of cells expressing Cdkn2a (which encodes p16INK4A, a commonly used marker of senescent cells ${ }^{117}$ ) increases in different tissues in old mice ${ }^{26}$. However, another single-cell analysis found no difference in $C d k n 2 a$ expression between young mice and old mice ${ }^{57}$, emphasizing current conceptual and technical limitations precluding identification of bona fide senescent cells in living organisms. A recent article reported scRNA-seq of p16INK $4 \mathrm{~A}^{\text {hi }}$ senescent cells with heterogeneous senescence-associated phenotypes in a reporter mouse model ${ }^{120}$. Interestingly, senescent cells include various cell types that are enriched in hepatic endothelium and renal proximal and distal tubule epithelia. Elimination of these p16INK4 $\mathrm{A}^{\text {hi }}$ senescent cells decreases immune infiltration in a model of metabolic liver disease ${ }^{120}$. Further studies are needed to better understand how heterogeneous senescent cells contribute to low-grade chronic inflammation and reshape immunity in ageing.

Interplay between immune and senescent cells. Recognition and elimination of senescent cells by specialized immune cells is a crucial step in maintaining tissue homeostasis and preventing maladaptive inflammation ${ }^{121}$ (FIG. 3). Components of the SASP, such as CCL2 and CCL7, attract immune cells, including macrophages, NK cells and $\mathrm{T}$ cells ${ }^{121-123}$. Senescent cells also recruit neutrophils ${ }^{36}$, tissue infiltration of which is one of the hallmarks of immune ageing. Macrophages can physically interact with and eliminate senescent cells in developmental and pathological processes $^{124-128}$. Whether the impaired phagocytosis by aged macrophages ${ }^{38}$ is causative for senescent cell accumulation in old tissues remains to be clarified. NK cells recognize and kill senescent cells to coordinate tissue remodelling ${ }^{129}$ and limit fibrogenic responses to acute tissue damage ${ }^{130}$. Intriguingly, the cytotoxic functions of NK cells and T cells appear to control the accumulation of senescent cells in ageing because mice lacking perforin 


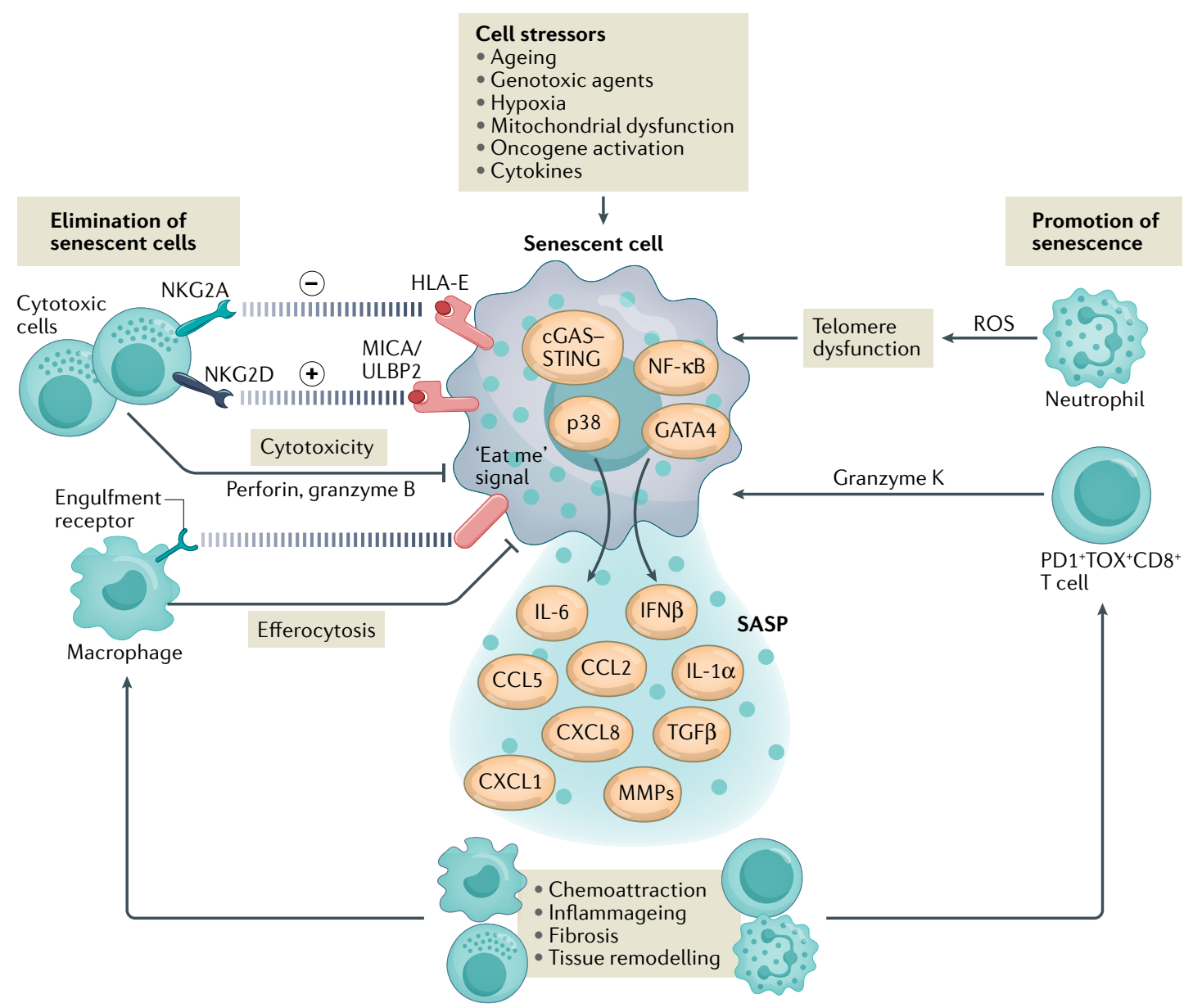

Fig. 3 | Interactions between immune and senescent cells. Senescent cells differentiate from various cell types in response to stress signals in ageing tissues. Senescent cells differ in their transcriptional signatures and show heterogeneity in the senescence-associated secretory phenotype (SASP) ${ }^{119}$. Innate immune signalling pathways (involving p38 mitogenactivated protein kinase and cGAS-STING pathways) and transcriptional factors (such as NK- $\kappa B$ and GATA4) induce cytokines and tissue remodelling factors that constitute the SASP ${ }^{175-179}$. Among the SASP components, growth factors (such as transforming growth factor- $\beta$ (TGF $\beta$ )) and matrix metalloproteinases (MMPs) increase tissue fibrosis, whereas chemokines and cytokines create a pro-inflammatory environment in ageing tissues. Chemokines of the SASP attract immune cells that can interact with, identify and eliminate senescent cells. Cytotoxic natural killer (NK) cells and CD8 ${ }^{+}$ $T$ cells recognize and kill senescent cells via a perforin-dependent mechanism ${ }^{129-131}$. This elimination of senescent cells is orchestrated by specific activating (MICA/ULBP2-NKG2D) and inhibitory (HLA-E-NKG2A) ligand-receptor interactions between senescent cells and cytotoxic cells ${ }^{180,181}$. Moreover, tissue macrophages can find and eliminate damaged and dying senescent cells by efferocytosis. By contrast, chemoattraction of neutrophils by the SASP components CXC-chemokine ligand 1 (CXCL1) and CXCL8 expand senescent cell load in ageing tissues. Neutrophils drive telomere dysfunction and induce senescence in bystander non-immune cells by generating reactive oxygen species (ROS) ${ }^{36}$. Accumulation of exhausted-like PD1 ${ }^{+} \mathrm{TOX}{ }^{+} \mathrm{CD} 8^{+} \mathrm{T}$ cells associated with ageing in old tissues can enhance expression of the SASP via pro-inflammatory granzyme K (GZMK) 25 . CCL, CC-chemokine ligand; IFN $\beta$, interferon- $\beta$.

(the crucial effector of cytotoxicity) exhibit both higher senescent-cell tissue burden and chronic inflammation while they age $\mathrm{e}^{131}$. Consistent with this is the observation of decreased frequencies of NK cells and replacement of tissue-resident $\mathrm{CD} 8^{+} \mathrm{T}$ cells with exhausted-like PD1 ${ }^{+}$ $\mathrm{T}$ cells in various tissues of aged mice ${ }^{25}$. In addition to cytotoxic $\mathrm{CD}^{+} \mathrm{T}$ cells, at least in the context of cellular senescence in cancer, $\mathrm{CD} 4^{+} \mathrm{T}$ cells also provide immune surveillance of premalignant senescent cells and require macrophages to eliminate them ${ }^{128}$. In mice, elimination of senescent cells via genetic manipulation can prevent or delay tissue dysfunction and extend 'healthspan' ${ }^{132,133}$ (the period of time an organism lives free of chronic diseases of ageing), suggesting that immune surveillance and elimination of senescent cells contribute to delay of age-related diseases. However, the immune cell-mediated elimination of senescent cells is context dependent and tightly regulated because a transitory accumulation of senescent cells is critical for tumour suppression and certain regenerative processes such as wound healing ${ }^{134}$.

\section{Immune ageing in mice versus humans}

Despite tremendous progress in single-cell techniques and their application to mouse immune ageing in various tissues, current single-cell data in humans are 
generally limited to immune cell populations from the blood (TABLE 1). Nevertheless, the comparison of available datasets shows a certain degree of similarity in how distinct immune cell subsets change with ageing in mice and humans. For example, monocytes increase in abundance whereas plasmacytoid dendritic cells decrease in abundance in both species when they age ${ }^{25,135,136}$. Similarly, naive $\mathrm{CD} 4^{+} \mathrm{T}$ cells and $\mathrm{CD} 8^{+} \mathrm{T}$ cells and populations of SOX4-expressing $\gamma \delta \mathrm{T}$ cells are less abundant in old mice and humans $\mathrm{s}^{25,137,138}$. Furthermore, cytotoxic $\mathrm{CD}^{+} \mathrm{T}$ cells and GZMK ${ }^{+} \mathrm{CD}^{+} \mathrm{T}_{\mathrm{EM}}$ cells universally accumulate during ageing in both species ${ }^{25,69,72}$. These findings suggest that mice and humans share unidentified age-related factors that similarly affect these immune cell populations. One of the candidates for this role might be a pro-inflammatory component of the SASP, a shared characteristic of old mice and humans. Importantly, unlike in laboratory mice, which usually live in specific-pathogen-free conditions, the immune system in humans is constantly reshaped by a history of infections, and a role for some chronic viral infections (such as cytomegalovirus infection) in immune ageing in humans is well documented ${ }^{139}$. This and other infections could explain the more complex pattern of age-associated alterations among $\mathrm{CD}^{+} \mathrm{T}$ cell subsets in older humans compared with mice. Moreover, this might be why there is no direct phenotypic similarity between age-associated B cells revealed by scRNA-seq in these species ${ }^{25}$. Furthermore, our understanding of how tissue-resident immune cells (including macrophages, $\mathrm{T}$ cells and ILCs) age in humans is minimal and will significantly benefit from future single-cell studies.

\section{Expanding the ageing paradigm}

Single-cell technologies have already significantly expanded the current paradigm of immune ageing. For example, they have made it possible to better understand the heterogeneity of human $\mathrm{CD}^{+} \mathrm{T}_{\mathrm{EM}}$ cells and distinguish between $\mathrm{GZMK}^{+}$and $\mathrm{GZMB}^{+} \mathrm{T}_{\mathrm{EM}}$ cell populations, revealing the $\mathrm{GZMK}^{+}$cells as the crucial age-associated $\mathrm{CD} 8^{+} \mathrm{T}_{\mathrm{EM}}$ cell subset in humans ${ }^{25}$. Single-cell analyses also defined cytotoxic $\mathrm{CD} 4^{+} \mathrm{T}$ cells as a key feature of immune ageing conserved between mice and humans ${ }^{69,72}$. In addition, combined single-cell sequencing of RNA and antigen receptors expanded our capability to study TCR and BCR repertoires to an unprecedented level. One of the recent discoveries stemming from this expanded toolbox is that the age-associated loss of TCR repertoire diversity in mouse $\mathrm{CD}^{+} \mathrm{T}$ cells appears to be driven primarily by the replacement of polyclonal naive $\mathrm{T}$ cells and $\mathrm{T}_{\mathrm{EM}}$ cells by oligoclonal $\mathrm{PD}^{+} \mathrm{TOX}^{+} \mathrm{CD} 8^{+} \mathrm{T}$ cells ${ }^{25}$. Finally, unbiased single-cell profiling of immune cells across multiple tissues led to the demonstration that a dietary intervention with a beneficial effect on healthspan not only reshapes age-disturbed immune landscapes but also specifically reprogrammes distinct pro-inflammatory macrophage subsets in rodents ${ }^{33}$. These results suggest an intriguing possibility that some immune cell populations might be a future target for anti-ageing therapies.

The next-generation profiling techniques will allow further exploration of the many remaining questions in the field of immune ageing. For instance, the interaction between immune cells and the ageing environment is an important avenue for investigation, including the need to understand which processes are driven by immune cells and which reflect adaptation of immune cells to the aged environment. Spatial transcriptomics and imaging cytometry can reveal spatial relationships between immune cells and non-immune cells and promise to solve this puzzle in an unbiased manner. Also, tissue-resident immune cell populations are not sufficiently studied in ageing humans. Thus, spatial techniques will be an essential foundation for human immune ageing research. This approach is especially important for a better understanding of immune responses to pathogens in older individuals, in which the severity of some (but not all) viral and bacterial infections - such as pneumococcal disease, influenza virus and COVID-19 - is profoundly increased compared with that in younger adults ${ }^{140-144}$. Single-cell analyses across individuals of different ages can discriminate between the effects of ageing and the effects of the infectious disease itself ${ }^{61}$, which will help to distinguish between age-associated changes and the immune mechanisms of diseases such as COVID-19 (REF. ${ }^{145}$ ).

Another frontier in single-cell immunology is multiplexing of orthogonal approaches to characterize the ageing immune system. For instance, a simultaneous characterization of hundreds and thousands of genes and proteins in individual immune cells (for example, using CITE-seq) will deepen the immune profiling and facilitate prediction and validation of immune cell functions in ageing. The same approach is valid for a combination of transcriptomics and epigenomics of ageing immune cells. Parallel application of scRNA-seq and single-cell assay for transposase-accessible chromatin using sequencing (scATAC-seq) has already demonstrated encouraging potential to decipher new regulatory programmes in age-associated immune cell populations of $\mathrm{CD}^{+} \mathrm{T}$ cells in mice and humans ${ }^{25}$ (TABLE 2). Therefore, combined scRNA-seq and scATAC-seq in individual cells can identify crucial functional states and the underlying epigenetic landscapes that adapt the immune system to the aged environment.

Cellular senescence has been associated with various age-related phenotypes and diseases, but further studies are needed to determine the causative roles of senescent cells in this context ${ }^{112}$. Overcoming the current conceptual and technical limitations of identifying bona fide senescent cells at the single-cell level, especially in vivo, is a significant challenge limiting our ability to capture the interactions between senescent and immune cells and better understand the role of the SASP in inflammageing. Possible approaches might rely on combined measurements of mRNAs and proteins alongside the specific functional markers of macromolecular damage in individual cells. Furthermore, despite the well-documented beneficial effect of targeted elimination of senescent cells $^{133,146,147}$, it remains to be understood how this affects the ageing immune system.

Finally, a challenging caveat in studying immune ageing is the profound diversity of ageing phenotypes in mice and humans. Because physiological manifestations 
Table 2 | Single-cell transcriptomic and epigenetic datasets of immune ageing

\begin{tabular}{|c|c|c|c|}
\hline Dataset $^{a}$ & Species and organs & Details & Ref. \\
\hline $\begin{array}{l}\text { Profiling of single cells } \\
\text { across the lifespan } \\
\text { in mice (Tabula Muris } \\
\text { Senis) }\end{array}$ & $\begin{array}{l}\text { Mouse immune and non-immune cells from the } \\
\text { bladder, bone marrow, brain, fat, heart and aorta, } \\
\text { kidney, large intestine, limb muscle, diaphragm, } \\
\text { liver, lung, mammary gland, pancreas, skin, } \\
\text { spleen, thymus, tongue and trachea }\end{array}$ & $\begin{array}{l}\text { scRNA-seq of total cells from male and female C57BL/6JN mice } \\
\text { from six age groups: } 1 \text { month (the equivalent of early human } \\
\text { childhood) to } 30 \text { months (the equivalent of a human centenarian). } \\
\text { This dataset contains scTCR-seq and scBCR-seq data }\end{array}$ & . \\
\hline $\begin{array}{l}\text { Profiling of immune } \\
\text { cells in young and old } \\
\text { mice }\end{array}$ & $\begin{array}{l}\text { Sorted mouse immune cells from the spleen, } \\
\text { liver, lung and peritoneal cavity }\end{array}$ & $\begin{array}{l}\text { scRNA-seq of CD } 45^{+} \text {cells from young (3-4 months) and } \\
\text { aged ( } 17-18 \text { months) male C57BL/6J mice. This dataset } \\
\text { contains scTCR-seq and scBCR-seq data. Because of selective } \\
\text { enrichment for CD } 45^{+} \text {cells, this dataset captures rare immune } \\
\text { cell populations in tissues }\end{array}$ & 25 \\
\hline $\begin{array}{l}\text { Mouse ageing cell atlas } \\
\text { in three organs }\end{array}$ & $\begin{array}{l}\text { Mouse immune and non-immune cells from the } \\
\text { spleen, lung and kidney }\end{array}$ & $\begin{array}{l}\text { scRNA-seq of total cells from young ( } 7 \text { months) and aged } \\
\text { (22-23 months) male C57BL/6J mice. This dataset contains } \\
\text { scTCR-seq and scBCR-seq data }\end{array}$ & 57 \\
\hline Mouse ageing lung atlas & Mouse single-cell suspensions of whole lungs & $\begin{array}{l}\text { scRNA-seq of total cells from young ( } 3 \text { months) and aged } \\
\text { ( } 24 \text { months) male C57BL/6N mice }\end{array}$ & 27 \\
\hline $\begin{array}{l}\text { Immune cells in young } \\
\text { and old mice }\end{array}$ & $\begin{array}{l}\text { Mouse cells from the meninges, bone marrow } \\
\text { and blood }\end{array}$ & $\begin{array}{l}\text { scRNA-seq of cells from young ( } 3 \text { months) and aged ( } 25 \text { months) } \\
\text { female C57BL/6] mice. This dataset contains scBCR-seq data }\end{array}$ & 96 \\
\hline $\begin{array}{l}\text { Analysis of immune cells } \\
\text { in young and aged mice }\end{array}$ & $\begin{array}{l}\text { Mouse immune cells from the spleen and } \\
\text { dentate gyrus }\end{array}$ & $\begin{array}{l}\text { scRNA-seq of CD } 45^{+} \text {cells from young ( } 3 \text { months) and } \\
\text { old ( } 18 \text { months) C } 57 \mathrm{BL} / 6 \text { mice }\end{array}$ & 47 \\
\hline $\begin{array}{l}\text { Ageing-associated } \\
\text { alterations in mammary } \\
\text { cells in mice }\end{array}$ & $\begin{array}{l}\text { Epithelial and stromal cells from mouse } \\
\text { mammary tissues }\end{array}$ & $\begin{array}{l}\text { scRNA-seq of cells from young ( } 3-4 \text { months) and aged } \\
\text { (13-14 months) virgin female C57BL/6] mice }\end{array}$ & 28 \\
\hline $\begin{array}{l}\text { Ageing-associated } \\
\text { alterations in adipose } \\
\text { tissue in mice }\end{array}$ & $\begin{array}{l}\text { Tissue-resident immune cells from young and } \\
\text { old gonadal adipose tissue }\end{array}$ & $\begin{array}{l}\text { scRNA-seq of CD } 45^{+} \text {cells from young ( } 2-3 \text { months) and aged } \\
\text { (18-24 months) male C57BL/6] mice }\end{array}$ & 50 \\
\hline $\begin{array}{l}\text { Effect of ageing on } \\
\mathrm{CD} 4^{+} \mathrm{T} \text { cells in mice }\end{array}$ & Mouse $\mathrm{CD} 4^{+} \mathrm{T}$ cells from the spleen & $\begin{array}{l}\text { scRNA-seq of CD4 } 4^{+} \mathrm{T} \text { cells from young (2-3 months) and aged } \\
\text { (22-24 months) C57BL/6] mice }\end{array}$ & \\
\hline $\begin{array}{l}\text { Single-cell atlas of } \\
\text { ageing in rats }\end{array}$ & $\begin{array}{l}\text { Rat immune and non-immune cells from the } \\
\text { liver, fat, kidney, aorta, skin and bone marrow }\end{array}$ & $\begin{array}{l}\text { scRNA-seq of total cells from young ( } 5 \text { months) and old } \\
\text { ( } 27 \text { months) male and female Rattus norvegicus. One group of old } \\
\text { rats was calorie restricted ( } 70 \% \text { of calories) starting at } 18 \text { months }\end{array}$ & 33 \\
\hline $\begin{array}{l}\text { Cells from wounds of } \\
\text { old mice }\end{array}$ & Mouse cells from entire wounds & $\begin{array}{l}\text { scRNA-seq of cells from skin wounds from aged ( } 24 \text { months) } \\
\text { C57BL/6JN mice with fast-healing and slow-healing trajectories }\end{array}$ & 109 \\
\hline $\begin{array}{l}\text { Cell composition in old } \\
\text { neurogenic niches }\end{array}$ & $\begin{array}{l}\text { Mouse cells from subventricular zone } \\
\text { neurogenic niche }\end{array}$ & $\begin{array}{l}\text { scRNA-seq of cells from subventricular zone from young } \\
\text { ( } 3 \text { months) and aged ( } 28-29 \text { months) male C57BL/6JN mice }\end{array}$ & 157 \\
\hline $\begin{array}{l}\text { PBMCs of healthy } \\
\text { young and older } \\
\text { individuals }\end{array}$ & $\begin{array}{l}\text { Human PBMCs from healthy non-obese } \\
\text { individuals }\end{array}$ & $\begin{array}{l}\text { scRNA-seq and CITE-seq ( } 39 \text { antibodies) of PBMCs from } \\
11 \text { young ( } 25-29 \text { years) and } 10 \text { older ( } 62-70 \text { years) male donors. } \\
\text { This dataset contains scTCR-seq data }\end{array}$ & 25 \\
\hline $\begin{array}{l}\text { PBMCs of young and } \\
\text { older healthy adults and } \\
\text { young and older adults } \\
\text { with COVID-19 }\end{array}$ & Human PBMCs & $\begin{array}{l}\text { scRNA-seq and scATAC-seq of PBMCs from young ( } 20-45 \text { years) } \\
\text { and older ( } 60-80 \text { years) male and female donors - healthy } \\
\text { or with COVID-19. This dataset contains scTCR-seq and } \\
\text { scBCR-seq data }\end{array}$ & 60 \\
\hline $\begin{array}{l}\text { PBMCs of } \\
\text { supercentenarians and } \\
\text { control adult individuals }\end{array}$ & $\begin{array}{l}\text { Human PBMCs from older individuals (controls) } \\
\text { and supercentenarians }\end{array}$ & $\begin{array}{l}\text { scRNA-seq of PBMCs from five controls ( } 50-80 \text { years) and seven } \\
\text { supercentenarians ( } 110 \text { years). This dataset contains scTCR-seq } \\
\text { data }\end{array}$ & 72 \\
\hline $\begin{array}{l}\text { Epigenetic landscapes } \\
\text { of aged immune cells in } \\
\text { mice and humans }\end{array}$ & Mouse splenocytes and human PBMCs & $\begin{array}{l}\text { scATAC-seq of mouse CD } 45^{+} \text {cells from the spleen of young } \\
\text { ( } 3-4 \text { months) and aged ( } 17-18 \text { months) male C } 57 \mathrm{BL} / 6 \mathrm{~J} \text { mice } \\
\text { and of human PBMCs from three young ( } 25-29 \text { years) and three } \\
\text { older ( } 62-70 \text { years) healthy male donors }\end{array}$ & 25 \\
\hline
\end{tabular}

CITE-seq, cellular indexing of transcriptomes and epitopes by sequencing; PBMCs, peripheral blood mononuclear cells; scATAC-seq, single-cell assay for transposase-accessible chromatin using sequencing; scBCR-seq, single-cell B cell receptor sequencing; scRNA-seq, single-cell RNA sequencing; scTCR-seq, single-cell T cell receptor sequencing. ${ }^{~}$ Datasets can be explored online through an Artyomov laboratory webpage.

of ageing depend on a combination of genotype, medical history and environment, it is crucial to understand how these factors impact the immune system during ageing. Furthermore, immune ageing can be studied in the context of various risk factors that affect healthspan. For example, genetic factors driving the variability of functional decline in ageing are recognized in multiple genetic association studies ${ }^{148}$. Future single-cell research can deepen our understanding of how these and other factors affect distinct populations of immune cells at different ages. In mouse models of immune ageing, this should prompt researchers to strictly control effects of ageing that are derivatives from associated physiological processes (for example, decreased activity and accumulation of adipose tissue). Similarly, single-cell analysis of the immune system from phenotypically and genetically 
diverse individuals of different ages will help to reveal important mechanisms of immune system adaptation to the aged environment. Adding the temporal dimension to single-cell studies (both cross-sectional and longitudinal) across the lifespan is a major future direction to deeply characterize individual trajectories of immune ageing in mice and humans. For example, following up time-resolved multidimensional changes in healthy immune ageing ${ }^{149}$ or different stages of the immune response to an infection in young hosts versus older hosts is a crucial future goal.

In conclusion, adding space, time, depth and diversity to single-cell research of immune ageing is the next goal of the field.

Published online 23 November 2021
1. López-Otín, C., Blasco, M. A., Partridge, L., Serrano, M. \& Kroemer, G. The hallmarks of aging. Cell 153, 1194-1217 (2013).

2. Partridge, L., Deelen, J. \& Slagboom, P. E. Facing up to the global challenges of ageing. Nature 561 45-56 (2018).

3. Nikolich-Žugich, J. The twilight of immunity: emerging concepts in aging of the immune system. Nat. Immunol. 19, 10-19 (2018)

4. Gomes, T., Teichmann, S. A. \& Talavera-López, C. Immunology driven by large-scale single-cell sequencing. Trends Immunol. 40, 1011-102 (2019).

5. Davis, M. M., Tato, C. M. \& Furman, D. Systems immunology: just getting started. Nat. Immunol. 18 725-732 (2017)

6. Franceschi, C. et al. Inflamm-aging: an evolutionary perspective on immunosenescence. Ann. N. Y. Acad Sci. 908, 244-254 (2006).

7. Franceschi, C., Garagnani, P., Parini, P., Giuliani, C. $\delta$ Santoro, A. Inflammaging: a new immune-metabolic viewpoint for age-related diseases. Nat. Rev. Endo. 14, 576-590 (2018).

8. Morrisette-Thomas, V. et al. Inflamm-aging does not simply reflect increases in pro-inflammatory markers. Mech. Ageing Dev. 139, 49-57 (2014).

9. Schaum, N. et al. Ageing hallmarks exhibit organ-specific temporal signatures. Nature $\mathbf{5 8 3}$ 596-602 (2020)

This study uses bulk RNA sequencing of multiple organs at ten ages across the mouse lifespan and reveals shifts in expression of genes clustered in consistent trajectory groups with coherent biological functions during ageing.

10. Baruch, K. et al. Aging-induced type I interferon response at the choroid plexus negatively affects brain function. Science 346, 89-93 (2014).

11. Sato, Y. \& Yanagita, M. Immunology of the ageing kidney. Nat. Rev. Neph. 15, 625-640 (2019).

12. Karin, O., Agrawal, A., Porat, Z., Krizhanovsky, V. ¿ Alon, U. Senescent cell turnover slows with age providing an explanation for the Gompertz law. Nat. Commun. 10, 5495 (2019).

13. Thompson, H. L., Smithey, M. J., Surh, C. D. \& Nikolich-Žugich, J. Functional and homeostatic impact of age-related changes in lymph node stroma. Front. Immunol. https://doi.org/10.3389/fimmu.2017.00706 (2017).

14. Yousefzadeh, M. J. et al. Tissue specificity of senescent cell accumulation during physiologic and accelerated aging of mice. Aging Cell 19, e13094 (2020).

15. Geiger, H., de Haan, G. \& Florian, M. C. The ageing haematopoietic stem cell compartment. Nat. Rev. Immunol. 13, 376-389 (2013)

16. Elyahu, Y. \& Monsonego, A. Thymus involution sets the clock of the aging T-cell landscape: Implications for declined immunity and tissue repair. Ageing Res. Rev. 65, 101231 (2021)

17. Dorshkind, K., Höfer, T., Montecino-Rodriguez, E. Pioli, P. D. \& Rodewald, H.-R. Do haematopoietic stem cells age? Nat. Rev. Immunol. 20, 196-202 (2020).

18. Rossi, D. J. et al. Cell intrinsic alterations underlie hematopoietic stem cell aging. Proc. Natl Acad. Sci. USA 102, 9194-9199 (2005).

19. Beerman, I. et al. Functionally distinct hematopoietic stem cells modulate hematopoietic lineage potential during aging by a mechanism of clonal expansion. Proc. Natl Acad. Sci. USA 107, 5465-5470 (2010).

20. Helbling, P. M. et al. Global transcriptomic profiling of the bone marrow stromal microenvironment during postnatal development, aging, and inflammation. Cell Rep. 29, 3313-3330.e4 (2019).

21. Tikhonova, A. N. et al. The bone marrow microenvironment at single-cell resolution. Nature 569, 222-228 (2019).
22. Shchukina, I. et al. Enhanced epigenetic profiling of classical human monocytes reveals a specific signature of healthy aging in the DNA methylome. Nat. Aging 1 124-141 (2021)

23. Reynolds, L. M. et al. Transcriptomic profiles of aging in purified human immune cells. BMC Genomics 16 333 (2015).

24. Bassler, K., Schulte-Schrepping, J.,

Warnat-Herresthal, S., Aschenbrenner, A. C. $\&$ Schultze, J. L. The myeloid cell compartment - cell by cell. Ann. Rev. Immunol. 37, 269-293 (2019).

25. Mogilenko, D. A. et al. Comprehensive profiling of an aging immune system reveals clonal $\mathrm{CZMK}^{+} \mathrm{CD} 8$ $T$ cells as conserved hallmark of inflammaging. Immunity 54, 99-115.e12 (2021).

This article provides single-cell transcriptomics and epigenomics of immune cells from young and old mouse tissues and human blood, and highlights key features of immune ageing in myeloid cells, $B$ cells and $T$ cells, including accumulation of $\mathrm{PD}^{+}{ }^{+} \mathrm{GZMK}^{+} \mathrm{CD}^{+}{ }^{+} \mathrm{T}$ cells in mice and $\mathrm{GZMK}{ }^{+} \mathrm{CD} 8$ $\mathrm{T}$ cells in humans.

26. Almanzar, N. et al. A single-cell transcriptomic atlas characterizes ageing tissues in the mouse. Nature 583, 590-595 (2020)

This article presents a scRNA-seq atlas across the mouse lifespan that includes data from 23 tissues and organs (Tabula Muris Senis).

27. Angelidis, I. et al. An atlas of the aging lung mapped by single cell transcriptomics and deep tissue proteomics. Nat. Commun. 10, 1-17 (2019).

28. Li, C. M. et al. Aging-associated alterations in mammary epithelia and stroma revealed by single-cell RNA sequencing. Cell Rep. 33, 108566 (2020).

29. Bodogai, M. et al. Commensal bacteria contribute to insulin resistance in aging by activating innate B1 a cells. Sci. Transl. Med. 10, eaat4271 (2018)

30. Linehan, E. et al. Aging impairs peritoneal but not bone marrow-derived macrophage phagocytosis. Aging Cell 13, 699-708 (2014).

31. Bian, Z. et al. Deciphering human macrophage development at single-cell resolution. Nature $\mathbf{5 8 2}$, 571-576 (2020)

32. Fontana, L. $\&$ Partridge, L. Promoting health and longevity through diet: from model organisms to humans. Cell 161, 106-118 (2015).

33. Ma, S. et al. Caloric restriction reprograms the single-cell transcriptional landscape of Rattus norvegicus aging. Cell 180, 984-1001.e22 (2020). This article shows that caloric restriction results in altered cell populations and reshaped transcriptional landscapes in tissues of old rats, including changes in immune cells resolved at single-cell levels.

34. Butcher, S., Chahel, H. \& Lord, J. M. Ageing and the neutrophil: no appetite for killing? Immunology 100 411-416 (2000)

35. Barkaway, A et al. Age-related changes in the local milieu of inflamed tissues cause aberrant neutrophil trafficking and subsequent remote organ damage. Immunity 54, 1494-1510.e7 (2021). This article shows that reverse transendothelial migration of neutrophils is increased in old mice, which is regulated by inflammatory factors including CXCL1 and can result in tissue damage.

36. Lagnado, A. et al. Neutrophils induce paracrine telomere dysfunction and senescence in ROS-dependent manner. EMBO J. 40, e106048 (2021).

37. Lu, R. J. et al. Multi-omic profiling of primary mouse neutrophils predicts a pattern of sex- and age-related functional regulation. Nat. Aging 1, 715-733 (2021)

38. Aprahamian, T., Takemura, Y., Goukassian, D. \& Walsh, K. Ageing is associated with diminished apoptotic cell clearance in vivo. Clin. Exp. Immunol. 152, 448-455 (2008)

39. Chougnet, C. A. et al. Loss of phagocytic and antigen cross-presenting capacity in aging dendritic cells is associated with mitochondrial dysfunction. J. Immunol. 195, 2624-2632 (2015).

40. Butcher S. K et al Senescence in innate immune responses: reduced neutrophil phagocytic capacity and CD16 expression in elderly humans. J. Leukoc Biol. 70, 881-886 (2001).

41. Wong, C. \& Goldstein, D. R. Impact of aging on antigen presentation cell function of dendritic cells. Curr. Opin. Immunol. 25, 535-541 (2013).

42. Vivier, E. et al. Innate lymphoid cells: 10 years on. Cell 174, 1054-1066 (2018)

43. Hazeldine, J. \& Lord, J. M. The impact of ageing on natural killer cell function and potential consequences for health in older adults. Ageing Res. Rev. 12 1069-1078 (2013).

44. Manser, A. R. \& Uhrberg, M. Age-related changes in natural killer cell repertoires: impact on NK cell function and immune surveillance. Cancer Immunol. Immunother. 65, 417-426 (2016).

45. Hazeldine, J., Hampson, P. \& Lord, J. M. Reduced release and binding of perforin at the immunological synapse underlies the age-related decline in natural killer cell cytotoxicity. Aging Cell 11, 751-759 (2012)

46. Chiu, B.-C., Martin, B. E., Stolberg, V. R. \& Chensue, S. W. The host environment Is responsible for aging-related functional NK cell deficiency. J. Immunol. 191, 4688-4698 (2013).

47. Jin, W.-N. et al. Neuroblast senescence in the aged brain augments natural killer cell cytotoxicity leading to impaired neurogenesis and cognition. Nat. Neurosci. 24, 61-73 (2021).

48. Bal, S. M., Golebski, K. \& Spits, H. Plasticity of innate lymphoid cell subsets. Nat. Rev. Immunol. 20, 552-565 (2020).

49. Bai, L. et al. Liver type 1 innate lymphoid cells develop locally via an interferon- $\gamma-$ dependent loop. Science 371, eaba4177 (2021)

50. Goldberg, E. L. et al. IL-33 causes thermogenic failure in aging by expanding dysfunctional adipose ILC2. Cell Metab. https://doi.org/10.1016/j.cmet.2021.08.004 (2021).

This study performs single-cell analyses of adipose tissue-resident immune cells in old mice and identifies the age-mediated decline in ILC2 functions as a cause of maladaptation to cold

51. Fung, I. T. H. et al. Activation of group 2 innate lymphoid cells alleviates aging-associated cognitive decline. J. Exp. Med. 217, e20190915 (2020).

52. D'Souza, S. S. et al. Compartmentalized effects of aging on group 2 innate lymphoid cell development and function. Aging Cell 18, e13019 (2019).

53. Brestoff, J. R. et al. Group 2 innate lymphoid cells promote beiging of white adipose tissue and limit obesity. Nature 519, 242-246 (2015).

54. Mittelbrunn, M. \& Kroemer, G. Hallmarks of T cell aging. Nat. Immunol. 22, 687-698 (2021).

55. Lerner, A., Yamada, T. \& Miller, R. A. Pgp-1 hi $T$ lymphocytes accumulate with age in mice and respond poorly to concanavalin A. Eur. J. Immunol. 19, 977-982 (1989)

56. Ku, C. C., Kappler, J. \& Marrack, P. The growth of the very large $\mathrm{CD} 8+\mathrm{T}$ cell clones in older mice is controlled by cytokines. J. Immunol. 166, 2186-2193 (2001).

57. Kimmel, J. C. et al. Murine single-cell RNA-seq reveals cell-identity- and tissue-specific trajectories of aging. Genome Res. 29, 2088-2103 (2019). This article presents single-cell transcriptomics of four mouse organs and characterizes tissue-specific alterations in transcriptional programmes of stromal and immune cells during ageing.

58. McLane, L. M., Abdel-Hakeem, M. S. \& Wherry, E. J. CD8 T cell exhaustion during chronic viral infection and cancer. Ann. Rev. Immunol. 37, 457-495 (2019).

59. Blank, C. U. et al. Defining 'T cell exhaustion' Nat. Rev. Immunol. 19, 665-674 (2019).

60. Zheng, Y. et al. A human circulating immune cell landscape in aging and COVID-19. Protein Cell 11, 740-770 (2020). 
61. Arthur, L. et al. Cellular and plasma proteomic determinants of COVID-19 and non-COVID-19 pulmonary diseases relative to healthy aging. Nat. Aging 1, 535-549 (2021).

This cross-sectional study of peripheral blood mononuclear cell profiles from 148 healthy donors and 71 patients with COVID-19 uses a mass cytometry panel of 35 markers and defines features of healthy human immune ageing including increases in the abundances of $\mathrm{GZMK}^{+} \mathrm{CD} 8^{+} \mathrm{T}$ cells and $\mathrm{CD} 25^{\text {low }} \mathrm{CD}^{+}{ }^{+} \mathrm{T}$ cells and changes in naive and central memory subsets, and parallels them with the response to COVID-19 in elderly individuals.

62. Wertheimer, A. M. et al. Aging and cytomegalovirus infection differentially and jointly affect distinct circulating T cell subsets in humans. J. Immunol. 192 2143-2155 (2014)

63. Linton, P. J., Haynes, L., Klinman, N. R. \& Swain, S. L. Antigen-independent changes in naive CD4 T cells with aging. J. Exp. Med. 184, 1891-1900 (1996).

64. Ernst, D. N. et al. Differences in the expression profiles of CD45RB, Pgp-1, and 3G11 membrane antigens and in the patterns of lymphokine secretion by splenic $C D 4^{+} \mathrm{T}$ cells from young and aged mice. J. Immunol. 145, 1295-1302 (1990).

65. Han, G.-M., Zhao, B., Jeyaseelan, S. \& Feng, J.-M Age-associated parallel increase of Foxp3 ${ }^{+} \mathrm{CD} 4_{+}$ regulatory and $\mathrm{CD} 44^{+} \mathrm{CD} 4^{+}$memory T cells in SJL/J mice. Cell. Immunol. 258, 188-196 (2009).

66. Lages, C. S. et al. Functional regulatory T cells accumulate in aged hosts and promote chronic infectious disease reactivation. J. Immunol. 181, 1835-1848 (2008)

67. Nishioka, T., Shimizu, J., lida, R., Yamazaki, S. \& Sakaguchi, S. CD4 ${ }^{+}$CD25+Foxp3 ${ }^{+} T$ cells and CD4 ${ }^{+} \mathrm{CD} 25$ Foxp3 ${ }^{+} \mathrm{T}$ cells in aged mice. J. Immunol. 176, 6586-6593 (2006).

68. Sharma, S., Dominguez, A. L. \& Lustgarten, J. High accumulation of T regulatory cells prevents the activation of immune responses in aged animals. J. Immunol 177, 8348-8355 (2006).

69. Elyahu, Y. et al. Aging promotes reorganization of the CD4 T cell landscape toward extreme regulatory and effector phenotypes. Sci. Adv. 5, eaaw8330 (2019).

This article profiles $\mathrm{CD4} 4^{+} \mathrm{T}$ cells from young and old mice and defines cytotoxic, exhausted and activated $T_{\text {reg }}$ cells as hallmarks of ageing in the $\mathrm{CD4}^{+} \mathrm{T}$ cell compartment.

70. Guo, X. et al. Global characterization of T cells in non-small-cell lung cancer by single-cell sequencing. Nat. Med. 24, 978-985 (2018).

71. Takeuchi, A. \& Saito, T. CD4 CTL, a cytotoxic subset of $C D 4^{+} \mathrm{T}$ cells, their differentiation and function. Front. Immunol. 8, 194 (2017).

72. Hashimoto, K. et al. Single-cell transcriptomics reveals expansion of cytotoxic CD4 T cells in supercentenarians. Proc. Natl Acad. Sci. USA 116, 24242-24251 (2019).

This study generates an scRNA-seq dataset for circulating immune cells in supercentenarians and describes accumulation of cytotoxic $\mathrm{CD}^{+}{ }^{+} \mathrm{T}$ cells in extremely old individuals.

73. Channappanavar, R., Twardy, B. S., Krishna, P. $\delta$ Suvas, $\mathrm{S}$. Advancing age leads to predominance of inhibitory receptor expressing CD4 T cells. Mech. Ageing Dev. 130, 709-712 (2009).

74. Shimada, Y., Hayashi, M., Nagasaka, Y., Ohno-Iwashita, Y. \& Inomata, M. Age-associated up-regulation of a negative co-stimulatory receptor PD-1 in mouse CD4 ${ }^{+} \mathrm{T}$ cells. Exp. Gerontol. 44 517-522 (2009).

75. Haynes, L., Eaton, S. M., Burns, E. M., Rincon, M. \& Swain, S. L. Inflammatory cytokines overcome age-related defects in CD4 T cell responses in vivo. J. Immunol. 172, 5194-5199 (2004).

76. Haynes, L., Linton, P. J., Eaton, S. M., Tonkonogy, S. L. ¿ Swain, S. L. Interleukin 2, but not other common gamma chain-binding cytokines, can reverse the defect in generation of CD4 effector T cells from naive T cells of aged mice. J. Exp. Med. 190, 1013-1024 (1999).

77. Tsukamoto, $\mathrm{H}$. et al. Age-associated increase in lifespan of naïve CD4 T cells contributes to T-cell homeostasis but facilitates development of functional defects. Proc. Natl Acad. Sci. USA 106 18333-18338 (2009).

78. Martinez-Jimenez, C. P. et al. Aging increases cell-to-cell transcriptional variability upon immune stimulation. Science 355, 1433-1436 (2017).
79. Maue, A. C. et al. Proinflammatory adjuvants enhance the cognate helper activity of aged CD4 T cells. J. Immunol. 182, 6129-6135 (2009).

80. Ouyang, X. et al. Potentiation of Th17 cytokines in aging process contributes to the development of colitis. Cell Immunol. 266, 208-217 (2011).

81. Huang, M.-C., Liao, J.-J., Bonasera, S., Longo, D. L. $\&$ Goetzl, E. J. Nuclear factor-kappaB-dependent reversal of aging-induced alterations in T cell cytokines. FASEB J. 22, 2142-2150 (2008)

82. Chen, H.-C. et al. IL-7-dependent compositional changes within the $\gamma \delta \mathrm{T}$ cell pool in lymph nodes during ageing lead to an unbalanced anti-tumour response. EMBO Rep. 20, e47379 (2019).

83. Ryu, S. et al. Ketogenic diet restrains aging-induced exacerbation of coronavirus infection in mice. eLife 10 e66522 (2021).

84. Foy, T. M., Aruffo, A., Bajorath, J., Buhlmann, J. E. $\&$ Noelle, R. J. Immune regulation by CD40 and its ligand GP39. Annu. Rev. Immunol. 14, 591-617 (1996).

85. Eaton, S. M., Burns, E. M. Kusser, K., Randall, T. D. $\&$ Haynes, L. Age-related defects in CD4 T cell cognate helper function lead to reductions in humoral responses. J. Exp. Med. 200, 1613-1622 (2004).

86. Callahan, J. E., Kappler, J. W. \& Marrack, P. Unexpected expansions of CD8-bearing cells in old mice. J. Immunol. 151, 6657-6669 (1993).

87. Britanova, O. V. et al. Age-related decrease in TCR repertoire diversity measured with deep and normalized sequence profiling. J. Immunol. 192, 2689-2698 (2014).

88. Qi, Q. et al. Diversity and clonal selection in the human T-cell repertoire. Proc. Natl Acad. Sci. USA 111, 13139-13144 (2014)

89. Egorov, E. S. et al. The changing landscape of naive $\mathrm{T}$ cell receptor repertoire with human aging. Front. Immunol. 9, 1618 (2018)

90. de Greef, P. C. et al. The naive T-cell receptor repertoire has an extremely broad distribution of clone sizes. elife 9, e49900 (2020).

91. Miller, R. A. The aging immune system: primer and prospectus. Science 273, 70-74 (1996)

92. Hao, Y., O'Neill, P., Naradikian, M. S., Scholz, J. L. \& Cancro, M. P. A B-cell subset uniquely responsive to innate stimuli accumulates in aged mice. Blood 118 1294-1304 (2011)

93. Rubtsov, A. V. et al. Toll-like receptor 7 (TLR7)-driven accumulation of a novel CD11 c+B-cell population is important for the development of autoimmunity. Blood 118, 1305-1315 (2011).

94. Rubtsova, K. et al. B cells expressing the transcription factor T-bet drive lupus-like autoimmunity. J. Clin. Invest. 127, 1392-1404 (2017).

95. Cancro, M. P. Age-associated B cells. Annu. Rev. Immunol. 38, 315-340 (2020).

96. Brioschi, S. et al. Heterogeneity of meningeal B cells reveals a lymphopoietic niche at the CNS borders. Science 373, eabf9277 (2021).

97. Rubtsova, K., Rubtsov, A. V., Cancro, M. P. \& Marrack, P. Age-associated B cells: a T-bet-dependent effector with roles in protective and pathogenic Immunity. J. Immunol 195, 1933-1937 (2015).

98. Russell Knode, L. M. et al. Age-associated B cells express a diverse repertoire of $\mathrm{VH}$ and $\mathrm{V}_{\kappa}$ genes with somatic hypermutation. J. Immunol. 198, 1921-1927 (2017).

99. Pioli, P. D., Casero, D., Montecino-Rodriguez, E. Morrison, S. L. \& Dorshkind, K. Plasma cells are obligate effectors of enhanced myelopoiesis in aging bone marrow. Immunity 51, 351-366.e6 (2019).

100. Singh, S. P. et al. Cell lines generated from a chronic lymphocytic leukemia mouse model exhibit constitutive Btk and Akt signaling. Oncotarget $\mathbf{8}$, 71981-71995 (2017).

101. Yang, Y. et al. CTLA-4 expression by B- 1 a B cells is essential for immune tolerance. Nat. Commun. 12, 525 (2021).

102. Lee-Chang, C. et al. Aging converts innate B1 a cells into potent $\mathrm{CD}^{+} \mathrm{T}$ cell inducers. J. Immunol. 196, 3385-3397 (2016).

103. Lee-Chang, C. et al. Accumulation of 4-1BBL+B cells in the elderly induces the generation of granzyme- $B$ $\mathrm{CD} 8{ }^{+} \mathrm{T}$ cells with potential antitumor activity. Blood 124, 1450-1459 (2014)

104. Buckley, C. D., Barone, F., Nayar, S., Bénézech, C. \& Caamaño, J. Stromal cells in chronic inflammation and tertiary lymphoid organ formation. Annu. Rev. Immunol. 33, 715-745 (2015).

105. Krausgruber, T. et al. Structural cells are key regulators of organ-specific immune responses. Nature 583, 296-302 (2020).
106. Tigges, J. et al. The hallmarks of fibroblast ageing. Mech. Ageing Dev. 138, 26-44 (2014).

107. Lynch, M. D. \& Watt, F. M. Fibroblast heterogeneity: implications for human disease. J. Clin. Invest. 128, 26-35 (2018)

108. Salzer, M. C. et al. Identity noise and adipogenic traits characterize dermal fibroblast aging. Cell 175 , 1575-1590.e22 (2018). This study uses single-cell transcriptomics and lineage tracing and reveals that dermal fibroblasts lose cell identity in ageing, which can be partially reversed by systemic metabolic changes such as caloric restriction.

109. Mahmoudi, S. et al. Heterogeneity in old fibroblasts is linked to variability in reprogramming and wound healing. Nature 574, 553-558 (2019).

110. Solé-Boldo, L. et al. Single-cell transcriptomes of the human skin reveal age-related loss of fibroblast priming. Comm. Biol. 3, 1-12 (2020)

111. Zhao, L. et al. Pharmacologically reversible zonation-dependent endothelial cell transcriptomic changes with neurodegenerative disease associations in the aged brain. Nat. Commun. 11, 4413 (2020).

112. Childs, B. G. et al. Senescent cells: an emerging target for diseases of ageing. Nat. Rev. Drug. Disc 16 718-735 (2017)

113. Coppé, J.-P., Desprez, P.-Y., Krtolica, A. \& Campisi, J. The senescence-associated secretory phenotype: the dark side of tumor suppression. Annu. Rev. Pathol. Mech. Dis. 5, 99-118 (2010).

114. Faget, D. V., Ren, Q. \& Stewart, S. A. Unmasking senescence: context-dependent effects of SASP in cancer. Nat. Rev. Cancer 19, 439-453 (2019).

115. Kuilman, T. et al. Oncogene-induced senescence relayed by an interleukin-dependent inflammatory network. Cell 133, 1019-1031 (2008).

116. Acosta, J. C. et al. A complex secretory program orchestrated by the inflammasome controls paracrine senescence. Nat. Cell Biol. 15, 978-990 (2013).

117. Di Micco, R., Krizhanovsky, V., Baker, D. \& d'Adda di Fagagna, F. Cellular senescence in ageing: from mechanisms to therapeutic opportunities. Nat. Rev. Mol. Cell Biol. 22, 75-95 (2021).

118. Hernandez-Segura, A. et al. Unmasking transcriptional heterogeneity in senescent cells. Curr. Biol. 27, 2652-2660.e4 (2017).

119. Wiley, C. D. et al. Analysis of individual cells identifies cell-to-cell variability following induction of cellula senescence. Aging Cell 16, 1043-1050 (2017).

120. Omori, S. et al. Generation of a p16 reporter mouse and its use to characterize and target p16high cells in vivo. Cell Metab. 32, 814-828.e6 (2020).

121. Kale, A., Sharma, A., Stolzing, A., Desprez, P.-Y. \& Campisi, J. Role of immune cells in the removal of deleterious senescent cells. Immun. Ageing 17, 16 (2020).

122. Freund, A., Orjalo, A. V., Desprez, P.-Y. \& Campisi, J. Inflammatory networks during cellular senescence: causes and consequences. Trends Mol. Med. 16, 238-246 (2010).

123. Antonangeli, F., Zingoni, A., Soriani, A. \& Santoni, A. Senescent cells: living or dying is a matter of NK cells. J. Leukoc. Biol. 105, 1275-1283 (2019).

124. Storer, M. et al. Senescence is a developmental mechanism that contributes to embryonic growth and patterning. Cell 155, 1119-1130 (2013).

125. Muñoz-Espín, D. et al. Programmed cell senescence during mammalian embryonic development. Cell 155, 1104-1118 (2013)

126. Yun, M. H., Davaapil, H. \& Brockes, J. P. Recurrent turnover of senescent cells during regeneration of a complex structure. eLife 4, e05505 (2015).

127. Xue, W. et al. Senescence and tumour clearance is triggered by $\mathrm{p} 53$ restoration in murine liver carcinomas. Nature 445, 656-660 (2007).

128. Kang, T.-W. et al. Senescence surveillance of pre-malignant hepatocytes limits liver cancer development. Nature 479, 547-551 (2011).

129. Brighton, P. J. et al. Clearance of senescent decidual cells by uterine natural killer cells in cycling human endometrium. eLife 6, e31274 (2017).

130. Krizhanovsky, V. et al. Senescence of activated stellate cells limits liver fibrosis. Cell 134, 657-667 (2008)

131. Ovadya, Y. et al. Impaired immune surveillance accelerates accumulation of senescent cells and aging. Nat. Commun. 9, 5435 (2018) This article shows that mice with impaired cell cytotoxicity because of perforin deficiency have increased accumulation of senescent cells in tissues, chronic inflammation and lower survival. 
132. Baker, D. J. et al. Clearance of p16Ink4a-positive senescent cells delays ageing-associated disorders. Nature 479, 232-236 (2011).

133. Baker, D. J. et al. Naturally occurring $p 16^{\text {Ink4a-positive }}$ cells shorten healthy lifespan. Nature 530, 184-189 (2016)

134. Demaria, M. et al. An essential role for senescent cells in optimal wound healing through secretion of PDGF-AA. Dev. Cell 31, 722-733 (2014).

135. Puchta, A. et al. TNF drives monocyte dysfunction with age and results in impaired anti-pneumococcal immunity. PLoS Pathog 12 e 1005368 (2016).

136. Loukov, D., Naidoo, A., Puchta, A., Marin, J. L. A \& Bowdish, D. M. E. Tumor necrosis factor drives increased splenic monopoiesis in old mice. J. Leuk. Biol. 100, 121-129 (2016).

137. Tong, Q.-Y. et al. Human thymic involution and aging in humanized mice. Front. Immunol. 11, 1399 (2020)

138. Li, M. et al. Age related human T cell subset evolution and senescence. Immun. Ageing 16, 24 (2019).

139. Jergoviić, M., Contreras, N. A. ¿ Nikolich-Žugich, J. Impact of $\mathrm{CMV}$ upon immune aging: facts and fiction. Med. Microbiol. Immunol. 208, 263-269 (2019).

140. Gordon, A. \& Reingold, A. The burden of influenza: a complex problem. Curr. Epidemiol. Rep. 5, 1-9 (2018)

141. Johnson, R. W. et al. The impact of herpes zoster and post-herpetic neuralgia on quality-of-life. BMC Med. 8 37 (2010)

142. Wroe, P. C. et al. Aging population and future burden of pneumococcal pneumonia in the United States. J. Infect. Dis. 205, 1589-1592 (2012).

143. Salje, $\mathrm{H}$. et al. Estimating the burden of SARS-CoV-2 in France. Science 369, 208-211 (2020).

144. Chowers, M. Y. et al. Clinical characteristics of the West Nile fever outbreak, Israel, 2000. Emerg. Infect. Dis. 7, 675-678 (2001).

145. Montgomery, R. R. \& Steen, H. Using 'big data' to disentangle aging and COVID-19. Nat. Aging 1 496-497 (2021)

146. Xu, M. et al. Senolytics improve physical function and increase lifespan in old age. Nat. Med. 24, 1246-1256 (2018)

147. Amor, C. et al. Senolytic CAR T cells reverse senescence-associated pathologies. Nature $\mathbf{5 8 3}$, 127-132 (2020)

148. Melzer, D. Pilling, L. C.\& Ferrucci, L. The genetics of human ageing. Nat. Rev. Genet. 21, 88-101 (2020)

149. Alpert, A. et al. A clinically meaningful metric of immune age derived from high-dimensional longitudinal monitoring. Nat. Med. 25, 487-495 (2019).

150. McQuattie-Pimentel, A. C. et al. The lung microenvironment shapes a dysfunctional response of alveolar macrophages in aging. J. Clin. Invest. 131, e140299 (2021).

151. Wong, C. K. et al. Aging impairs alveolar macrophage phagocytosis and increases influenza-induced mortality in mice. J. Immunol. 199, 1060-1068 (2017).

152. Ide, S. et al. Yolk-sac-derived macrophages progressively expand in the mouse kidney with age. elife 9, e51756 (2020)

153. Wong, C. P., Magnusson, K. R. \& Ho, E. Aging is associated with altered dendritic cells subset distribution and impaired proinflammatory cytokine production. Exp. Gerontol. 45, 163-169 (2010).

154. Pieren, D. K. J., Smits, N. A. M., van de Garde, M. D. B. \& Guichelaar, T. Response kinetics reveal novel features of ageing in murine T cells. Sci. Rep 9,5587 (2019).

155. Bapat, S. P. et al. Depletion of fat-resident Treg cells prevents age-associated insulin resistance. Nature 528, 137-141 (2015).

156. Quinn, K. M. et al. Age-related decline in primary $\mathrm{CD}^{+} \mathrm{T}$ cell responses is associated with the development of senescence in virtual memory CD8 T cells. Cell Rep. 23, 3512-3524 (2018)

157. Dulken, B. W. et al. Single-cell analysis reveals T cell infiltration in old neurogenic niches. Nature 571, 205-210 (2019).

This study uses single-cell transcriptomics of neurogenic niches in mice and identifies an infiltration of $\mathrm{T}$ cells that express IFN $\gamma$ in old neurogenic niches and can suppress the proliferation of neural stem cells.
158. Chiu, B.-C., Martin, B. E., Stolberg, V. R. \& Chensue, S. W. Cutting edge: central memory CD8 T cells in aged mice are virtual memory cells. J. Immunol. 191, 5793-5796 (2013)

159. Clambey, E. T., White, J., Kappler, J. W. \& Marrack, P. Identification of two major types of age-associated CD8 clonal expansions with highly divergent properties. Proc. Natl Acad. Sci. USA 105, 12997-13002 (2008).

160. Lee, K.-A. et al. Characterization of age-associated exhausted $\mathrm{CD}^{+} \mathrm{T}$ cells defined by increased expression of Tim-3 and PD-1. Aging Cell 15, 291-300 (2016).

161. Seidler, S., Zimmermann, H. W., Bartneck, M. Trautwein, C. \& Tacke, F. Age-dependent alterations of monocyte subsets and monocyte-related chemokine pathways in healthy adults. BMC Immunol. 11, 30 (2010).

162. Stervbo, U. et al. Effects of aging on human leukocytes (part I): immunophenotyping of innate immune cells. Age 37, 92 (2015)

163. Rodriguez-Zhurbenko, N., Quach, T. D., Hopkins, T. J., Rothstein, T. L. \& Hernandez, A. M. Human B-1 cells and B-1 cell antibodies change with advancing age. Front. Immunol. 10, 483 (2019).

164. van der Geest, K. S. M. et al. Impact of aging on the frequency, phenotype, and function of CD 161expressing T cells. Front. Immunol. https://doi.org/ 10.3389/fimmu.2018.00752 (2018).

165. Colonna-Romano, G. et al. Impairment of gamma/ delta T lymphocytes in elderly: implications for immunosenescence. Exp. Gerontol. 39, 1439-1446 (2004).

166. Tan, C. T. Y. et al. V $\delta 2+$ and $\alpha / \beta$ T cells show divergent trajectories during human aging. Oncotarget 7 , 44906-44918 (2016).

167. Michishita, Y. et al. Age-associated alteration of $\gamma \delta$ T-cell repertoire and different profiles of activation-induced death of $\mathrm{V} \delta 1$ and $\mathrm{V} \delta 2 \mathrm{~T}$ cells. Int. $\mathrm{J}$. Hematol. 94, 230-240 (2011)

168. Oishi, Y. \& Manabe, I. Macrophages in age-related chronic inflammatory diseases. NPJ Aging Mech. Dis. 2, 1-8 (2016)

169. Minhas, P. S. et al. Restoring metabolism of myeloid cells reverses cognitive decline in ageing. Nature $\mathbf{5 9 0}$, 122-128 (2021)

170. Ferrucci, L. \& Fabbri, E. Inflammageing: chronic inflammation in ageing, cardiovascular disease, and frailty. Nat. Rev. Cardio. 15, 505-522 (2018).

171. Desdín-Micó, G. et al. T cells with dysfunctional mitochondria induce multimorbidity and premature senescence. Science 368, 1371-1376 (2020). This article shows that TFAM-deficient T cells with dysfunctional mitochondria increase inflammageing, accelerate senescence and regulate organismal fitness and lifespan in mice.

172. Shenoy, A. T. \& Mizgerd, J. P. Seedy CD8+ T RM cells in aging lungs drive susceptibility to pneumonia and sequelae. Cell. Mol. Immunol. 18, 787-789 (2021).

173. Covarrubias, A. J. et al. Senescent cells promote tissue $\mathrm{NAD}^{+}$decline during ageing via the activation of CD38+ macrophages. Nat. Metab. 2, 1265-1283 (2020).

174. Chini, C. C. S. et al. CD38 ecto-enzyme in immune cells is induced during aging and regulates $\mathrm{NAD}^{+}$and NMN levels. Nat. Metab. 2, 1284-1304 (2020).

175. Freund, A., Patil, C. K. \& Campisi, J. p38MAPK is a novel DNA damage response-independent regulato of the senescence-associated secretory phenotype. EMBO J. 30, 1536-1548 (2011).

176. Acosta, J. C. et al. Chemokine signaling via the CXCR2 receptor reinforces senescence. Cell 133, 1006-1018 (2008).

177. Kang, C. et al. The DNA damage response induces inflammation and senescence by inhibiting autophagy of GATA4 Science 349, aaa5612 (2015).

178. Glück, S. et al. Innate immune sensing of cytosolic chromatin fragments through cGAS promotes senescence. Nat. Cell Biol. 19, 1061-1070 (2017).

179. Dou, Z. et al. Cytoplasmic chromatin triggers inflammation in senescence and cancer. Nature $\mathbf{5 5 0}$, 402-406 (2017)

180. Sagiv, A. et al. NKG2D ligands mediate immunosurveillance of senescent cells. Aging 8 328-344 (2016)
181. Pereira, B. I et al Senescent cells evade immune clearance via HLA-E-mediated NK and CD8 ${ }^{+} \mathrm{T}$ cell inhibition. Nat. Commun. 10, 1-13 (2019).

182. Papalexi, E. \& Satija, R. Single-cell RNA sequencing to explore immune cell heterogeneity. Nat. Rev. Immunol. 18, 35-45 (2018)

183. Stoeckius, M. et al. Simultaneous epitope and transcriptome measurement in single cells. Nat. Methods 14, 865-868 (2017).

184. Cusanovich, D. A. et al. Multiplex single-cell profiling of chromatin accessibility by combinatorial cellular indexing. Science 348, 910-914 (2015).

185. Lareau, C. A. et al. Droplet-based combinatorial indexing for massive-scale single-cell chromatin accessibility. Nat. Biotech. 37, 916-924 (2019).

186 . Cao, J. et al. Joint profiling of chromatin accessibility and gene expression in thousands of single cells. Science 361, 1380-1385 (2018).

187. Giesen, C. et al. Highly multiplexed imaging of tumor tissues with subcellular resolution by mass cytometry. Nat. Methods 11, 417-422 (2014).

188. Ståhl, P. L et al. Visualization and analysis of gene expression in tissue sections by spatial transcriptomics. Science 353, 78-82 (2016).

189. Gong, H., Do, D. \& Ramakrishnan, R. Single-cell mRNA-seq using the Fluidigm $\mathrm{C} 1$ system and integrated fluidics circuits. Methods Mol. Biol. 1783 193-207 (2018).

190. Utada, A. S. et al. Monodisperse double emulsions generated from a microcapillary device. Science $\mathbf{3 0 8}$ 537-541 (2005)

191. Picelli, S. et al. Full-length RNA-seq from single cells using Smart-seq2. Nat. Protoc. 9, 171-181 (2014).

192. Sharpless, N. E. \& Sherr, C. J. Forging a signature of in vivo senescence. Nat. Rev. Cancer 15, 397-408 (2015)

193. Gorgoulis, V. et al. Cellular senescence: defining a path forward. Cell 179, 813-827 (2019).

194. He, S. \& Sharpless, N. E. Senescence in health and disease. Cell 169, 1000-1011 (2017).

195. Grosse, L. et al. Defined p16high senescent cell types are indispensable for mouse healthspan. Cell Metab. 32, 87-99.e6 (2020).

196. Neurohr, G. E. et al. Excessive cell growth causes cytoplasm dilution and contributes to senescence. Cell 176, 1083-1097.e18 (2019).

197. Lee, B. Y. et al. Senescence-associated betagalactosidase is lysosomal beta-galactosidase. Aging Cell 5, 187-195 (2006).

198. Furman, D. et al. Chronic inflammation in the tiology of disease across the life span. Nat. Med. 25 1822-1832 (2019).

\section{Acknowledgements}

The authors thank L. Arthur for editing the manuscript. The work was supported by a grant from the Aging Biology Foundation (to M.N.A.).

\section{Author contributions}

The authors contributed equally to all aspects of the article.

\section{Competing interests}

The authors declare no competing interests.

Peer review information

Nature Reviews Immunology thanks G. Pawelec, S. Shen-Orr and the other, anonymous, reviewer(s) for their contribution to the peer review of this work.

\section{Publisher's note}

Springer Nature remains neutral with regard to jurisdictional claims in published maps and institutional affiliations.

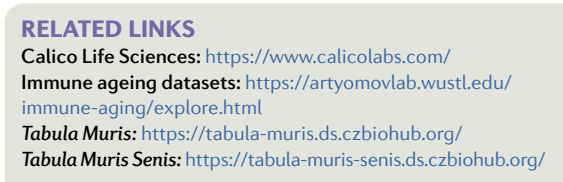

(C) Springer Nature Limited 2021 